\title{
Stadt und Reformation: Stand und Aufgaben der Forschung*
}

\author{
Von Kaspar von Greyerz
}

Vor 22 Jahren erschien Bernd Moellers wichtiges Buch zum Thema "Reichsstadt und Reformation“ (Moeller 1962). Unter Einbezug der spätmittelalterlichen Vorgeschichte untersuchte Moeller die frühe Breiten- und Tiefenwirkung, die dem Anliegen der Reformatoren in den deutschen Reichsstädten und in den größeren Städten der Schweiz zuteil geworden war. In der Arh wie die reformatorische Lehre von den städtischen Bürgerschaften aufgenommen wurde, erkannte er eine enge Verbindung, die diese Lehre mit dem städtisch-korporativen Gemeinschaftsgedanken einging, und damit eine Linie der Kontinuität, die die spätmittelalterlichen Bürgerbewegungen mit den frühen reformatorischen Bewegungen der Städte verband. Moeller betonte, daß das religiöse Anliegen vor allem der oberdeutschen Reformatoren und der in der Stadtgemeinde eingebettete Gemeinschaftsgedanke sich gegenseitig aufgrund einer inneren Affinität zu revitalisieren vermochten.

Bei näherer Betrachtung dieser Affinität fiel Moeller ein deutlicher Unterschied auf zwischen der reichsstädtischen Reformation Norddeutschlands und Frankens, die sich von Anfang an der Wittenberger Reformation zuwandte, und der oberdeutschen des schwäbisch-alemannischen Raums, die sich zunächst (mit Ausnahme Reutlingens) der Lehre Zwinglis und Bucers anschloß. In diesen oberdeutschen Städten, so folgerte Moeller, entstand eine besonders ausgeprägte Kongruenz zwischen einer städtisch geprägten reformatorischen Theologie und städtisch-genossenschaftlichem Selbstverständnis. Demgegenüber vermochte die Heilslehre Luthers mit ihren mehr individualisierenden

* Erweiterte und zuletzt im Sommer 1984 überarbeitete Fassung eines am 12. November 1982 am Institut für Europäische Geschichte in Mainz zum gleichen Thema gehaltenen Tagungsvortrags. Nur bis Ende 1983 erschienene Untersuchungen konnten berücksichtigt werden. Für wertvolle Informationen fühle ich mich zahlreichen Reformationshistorikern gegenüber zu Dank verpflichtet. Besonderer Dank gilt Peter Blickle und HansChristoph Rublack für ihre hilfreiche Kritik.

Zur Zitierweise: Sämtliche einschlägigen, im Text und Anmerkungsteil erwähnten und bis Ende 1983 erschienenen Arbeiten sind mit vollständigem Titel im anschließenden Verzeichnis zitierter Publikationen aufgefürt. Noch unveroffentlichte Studien und seit Ende 1983 erschienene Untersuchungen sind nur im Anmerkungsteil verzeichnet. Bei Hinweisen auf noch nicht publizierte Arbeiten wird auf die Angabe von Seitenzahlen verzichtet.

6 . 
Tendenzen der norddeutschen und fränkischen Stadtreformation weniger intensive Impulse zu vermitteln.

Dem theologischen Unterschied zwischen niederdeutscher und oberdeutscher Reformation entsprach somit nach Moeller im städtischen Bereich ein solcher in der Verfassungs- und Sozialstruktur. Damit ergab sich ein wesentliches, diese Elemente verbindendes Moment der geistigen Kontinuität zwischen spätmittelalterlicher und reformatorischer Reichsstadt. In einem 1964 erschienenen Aufsatz hat Moeller diese Interpretation erweitert und vertieft. Die angesprochene Kontinuität in den evangelischen freien Städten Oberdeutschlands bezeichnete er nun sogar als ${ }_{n}$ die höchste Aufgipfelung und Vertiefung des Mittelalters" (Moeller 1964, 161).

Von diesen Untersuchungen Bernd Moellers ist im Lauf der letzten zwanzig Jahre eine ungeheuer belebende Wirkung auf die deutsche und anglo-amerikanische Reformationsforschung ausgegangen, die in einer reichen $\mathrm{Zahl}$ von $\mathrm{Pu}$ blikationen ihren Ausdruck gefunden hat. 1978 hat Hans-Christoph Rublack einen ersten Forschungsbericht zum Thema "Stadt und Reformation“ vorgelegt, der die einschlägigen Untersuchungen bis zum Jahr 1976 aufarbeitet (Rublack 1978 a). Die letzte, knapp zusammenfassende Darstellung des hier behandelten Themenkomplexes hat 1981 der Kirchenhistoriker Gerhard Müller (Müller 1981) vorgelegt. Sie bietet eine kurze Zusammenfassung der Forschungstradition dieses Jahrhunderts, die Müller in Bernd Moellers "Reichsstadt und Reformation " aufgehoben und weitergeführt sieht. Die sich aus diesem Überblick und aus der jüngeren Diskussion der Begriffe "evangelische" bzw. nreformatorische Bewegungen " ergebenden Ansätze und Fragen bringt er sodann in eine knappe, auf die Nürnberger Reformation der 1520 er Jahre bezogene Studie zur Rezeption evangelischer Verkündigung ein.

Im folgenden werde ich mich, im Anschluß an den Forschungsbericht HansChristoph Rublacks, vornehmlich auf die Forschung der vergangenen sieben Jahre beschränken, ohne freilich im Einzelnen den Rückgriff auf frühere Untersuchungen vermeiden zu können und zu wollen. Dabei soll weniger additiv, im Sinne einer Aneinanderreihung von Rezensionen, sondern diskursiv und problem-orientiert verfahren werden. Meine Ausführungen gliedern sich in drei Teile. Erstens werde ich auf die seit 1976 um Bernd Moellers Interpretament der reichsstädtischen Reformation entbrannte Forschungskontroverse eingehen; zweitens widme ich mich im Rahmen der unter dem gestellten Thema angesprochenen Fragenkomplexe den seit 1976 erzielten Fortschritten; und drittens soll in der Form abschließender Bemerkungen auf offene Fragen und weitere Aufgaben, soweit diese nicht schon im zweiten Teil ausfuhrlich berührt wurden, hingewiesen werden. 


\section{GESELLSCHAFT, RELIGION UND VERFASSUNG IN DER STADTREFORMATION. ZUR JÜNGEREN DISKUSSION DIVERGIERENDER INTERPRETATIONEN.}

Im Laufe der letzten acht Jahre sind seitens englischer und amerikanischer Sozialhistoriker Zweifel an der Moellerschen Sicht der deutschen Stadt des Spätmittelalters als "corpus christianum im kleinen" (Moeller 1962, 15) laut geworden. In einem 1975 erschienenen Aufsatz zur Erfurter Reformation kritisiert Bob Scribner Moeller dahingehend, daß dieser den Einfluß sozialen Konflikts auf den Vorgang der Einführung städtischer Reformationen minimalisiere ${ }^{1}$ Zum ersten Mal kommt hier die Theorie sozialen Konflikts zur Sprache, die in der weiteren Kontroverse bis heute eine wichtige Rolle gespielt hat. Ein zweites wichtiges Thema dieser Kontroverse klingt erstmals in einem Aufsatz Scribners zur Frage "Why was there no Reformation in Cologne?" an (Scribner 1976) ${ }^{2}$. Scribner untersucht die äußeren und inneren Faktoren, die einer Einführung der Reformation in Köln entgegenstanden. Er verweist $u$. a. auf eine nicht unbedeutende, pro-reformatorische Gruppe unter den Handwerkern der rheinischen Reichsstadt. Tatsächlich vermochte sich aber diese Gruppe nicht als reformatorische Bewegung zu konstituieren. Scribner sieht dies darin begründet, daß die Rats- und Zunftaristokratie Kölns dank ihrer oligarchischen Stellung von Anfang an in der Lage war, durch wirkungsvolle Sozialkontrolle die Ausbildung einer derartigen Bewegung innerhalb der Gemeinde zu verhindern. Diese Kontrolle nahm insbesondere nach 1525 deutlich zu, weil der Rat nun sämtliche evangelische Regungen innerhalb der Gemeinde mit Anzeichen potentiellen sozialen Aufruhrs gleichsetzte: „All measures taken to strengthen the council's control were simultaneously measures against the Reformation" (Scriber 1976, 240).

Unter der Themenstellung ${ }_{n}$ Sozialkontrolle und die Möglichkeit einer städtischen Reformation" hat Scribner die am Beispiel Kölns gewonnenen Ergebnisse zu verallgemeinern versucht (Scribner 1978). Unter "Sozialkontrolle" wird dabei bewußt vereinfachend folgendes verstanden: „die Kräfte, welche die bestehende Ordnung erhalten, das Fortbestehen der politischen Macht ermöglichen und den Einfluß politischer auf gesellschaftliche Formen erlauben" (Scribner 1978 , 58). Wichtig ist seine Feststellung, daß wir „eine breite Auswahl von Städ-

1. Scribner 1975 a, 29: "Moeller minimized the influence of social conflict on the manner and forms in which the Reformation was adopted." - Kritisch zu einem anderen Aspekt dieser Studie Scribners: Lutz 1979, 139.

2. Die Bedeutung dieses Aufsatzes ist offenbar umstritten. Siehe Petri 1980 a, XI, und Press 1980 a, 267, Anm. 67. 
ten sehr genau untersuchen müssen, bevor ein zusammenfassendes Urteil möglich ist". Dazu formuliert er sog. "heuristische Richtlinien", die ich hier stark gekürzt wiedergebe (s. Scribner 1978, 63-64).

1. „Um festen Fuß zu fassen, muß sich die Reformationsbewegung in gemeinschaftlichen oder genossenschaftlichen Formen ausdrücken können ..."

2. "Wenn eine reformatorische Bewegung Unterstützung von seiten des Magistrats findet, werden die Sozialkontrolle und der darauf basierende Consensus kaum ernsthaft in Frage gestellt. Die Regierung kann die Reformation sogar als deren Stärkung ansehen ..."

3. "Wenn die Bewegung keine obrigkeitliche Zustimmung findet, kann sie sich nicht innerhalb der Schranken der Sozialkontrolle entfalten. Ihr Fortschritt ist von dem Maß der Lockerheit der Sozialkontrolle abhängig ..."

4. "Eine Bewegung, die sich nicht zufrieden gibt, innerhalb der Schranken der Sozialkontrolle zu bleiben, muß sich zur oppositionellen Bewegung entwikkeln ... Abgesehen von einem Stimmungswechsel im Magistrat kann sie nur durch Störung der bestehenden Ordnung auf Erfolg hoffen und läuft deshalb Gefahr, mit sozialer und politischer Opposition identifiziert zu werden.“

Bernd Moeller hat in diesem Ansatz eine analytische ${ }_{n}$ Betrachtungsweise und Deutung des Sozialgebildes Stadt“ gesehen, die er von seiner nintegrative(n) Betrachtungsweise" unterscheidet (Moeller 1978 2, 180). Der Unterschied besteht im wesentlichen über das rein Methodologische hinaus darin, daß Scribner zur Einsicht gelangt, daß das von Moeller beschriebene Bemühen um einen städtisch-gemeinschaftlichen Konsens unter bestimmten Bedingungen in eine nicht nur politische, sondern auch soziale Konfrontation von obrigkeitlicher Ratsherrschaft und städtischer Gemeinde (oder von Teilen derselben) als Untertanen umschlagen konnte. Moellers Verdienst sieht Scribner darin, daß er gegenüber der älteren Fragestellung, wie die Reformation die Gesellschaft umgestaltet habe, zur ursprunglicheren Frage zuruckgekehrt sei nof how the Reformation was shaped by the social context in which it arose". Er bemängelt aber, daß sich Moeller die Beantwortung seiner Fragestellung dadurch verbaue, daß er ein vereinfachendes Bild der Stadt jener Zeit als statisches Sozialgefüge zum Werte-Idealtyp uberhöhe (Scribner 1977 b, 483-84).

Dieselbe, gegen Moellers Interpretament gerichtete Argumentation hat auch Thomas A. Brady in seinem 1978 erschienenen Buch „Ruling Class, Regime and Reformation at Strasbourg, 1520-1555“ (Brady 1978 a) mit Nachdruck verfochten. Da inzwischen verschiedene ausführliche Besprechungen dieser Monographie vorliegen, kann hier auf eine genauere Inhaltsangabe verzichtet werden (s. z. B. Moeller 1980 a; Schindling 1981; Rapp 1982). Moellers Sicht der spätmittelalterlichen Stadt als "sacral corporation" wird von Brady einer eingehenden 
Kritik unterzogen (Brady 1978 a, 5 et passim). Für Straßburg selbst stellt Brady fest, daß der städtische Rat, der sich aus einer Aristokratie von Rentiers und Kaufleuten rekrutierte, in der Krise von 1523 bis 1525 dem Druck von „unten“ nachgebend entscheidende reformatorische Neuerungen einführte, um sich seine Herrschaft zu erhalten. Zwanzig Jahre später geriet dann die Straßburger Ratsoligarchie - nach Bradys Darstellung - 1547/48 in eine schwere Krise, da nun der schon lange schwelende Konflikt zwischen einer zwinglianisch gefärbten Partei unter Führung von Claus Kniebis und der gemäßigteren, von Jacob Sturm angeführten Richtung offen ausbrach und zur Emigration einer Reihe aristokratischer Familien führte. Vor allem unter den kleineren Handwerkern der Stadt erhob sich die Stimme des fortgesetzten Widerstandes gegen Kaiser und Reich. Innerhalb der entsprechenden Handwerkerzünfte, folgert Brady, ist der soziale Nährboden ("the proper social home") des Ideals der Gemeinde als sakraler Korporation zu finden (Brady 1978 a, 269).

Die zweite von Bernd Moeller entwickelte Argumentationslinie, die das besondere Echo betont, das die städtisch geprägte Theologie Zwinglis und Bucers in den oberdeutschen Reichsstädten fand, hat weniger Kritik auf sich gezogen. Ergänzt wurde sie durch Heinz Schilling im bezug auf die Städte Nord- und Nordwestdeutschlands, kritisiert durch Martin Brecht. An der noch andauernden Kontroverse um Moellers integrative Betrachtungsweise haben diese Einwände keinen wesentlichen Anteil gehabt. Sie können daher erst weiter unten in unsere Betrachtungen einfließen.

Die von Bernd Moeller, Heinz Schilling, Anton Schindling u.a. an Scribners und vor allem Bradys analytischer Betrachtungsweise geübte Kritik läßt sich im wesentlichen in vier Punkte zusammenfassen ${ }^{3}$.

1. Die sozialen Spannungen werden von Brady gleichsam "überfordert", wenn sie den Erfolg der Reformation in Straßburg verständlich machen sollen (Moeller 1979 a, 28-29; ähnlich Schilling 1981, 376, Anm.17 a, und Schindling 1981, 178).

2. Brady wird Unklarheit vorgeworfen, wenn er den Appell an die Gemeinschaft zunächst als Herrschaftsinstrument darstellt, andererseits aber beobachtet, daß dieser Appell $1547 / 48$ in Straßburg "von kleinen unabhängigen Hand-

3. Hinzuweisen ist hier zunächst auf den anläßlich einer Tagung des Deutschen Historischen Instituts London im Mai 1978 gefuhrten Meinungsaustausch. Dazu Moeller 1979 a, und das Moellers Kritik unterstutzende Votum Steven Ozments (Ozment 1979), sowie die Repliken Bradys und Scribners (Brady 19792; Scribner 1979a) und Brady 1979 b. - Siehe weiterhin Moeller 1980 a; Schilling 1981, 16, Anm. 16, und 376, Anm. 17 a; sowie Schindling 1981, 175-79. 
werkern und Handeltreibenden ... gerade gegen die Herrschenden gewendet wurde“ (Moeller 1979a, 29; Moeller 1980 a, 110).

3. Die Rezensenten sehen eine grundlegende Schwäche der Studie Bradys darin, daß er geistige und religiöse Faktoren vernachlässigt. Moeller illustriert diesen Punkt durch die Kritik an Bradys Darstellung des Straßburger Bildersturms von 1523, der von diesem hauptsächlich als Angriff gegen die Aristokratie als Bilderstifter interpretiert wird (Moeller 1979 a, 29; Moeller 1980 a, 111112).

4. Das Konfliktmodell Bradys wird der Kritik unterzogen. Dazu Heinz Schilling: „Wie in der Religionssoziologie trägt Brady m. E. auch in der Konflikttheorie anachronistische Ansprüche an die frühneuzeitliche Stadtherrschaft heran und verstellt sich dadurch zentrale Einsichten (Schilling 1981, 376, Anm. 17 a).

Die damit skizzierte Forschungskontroverse ist von grundsätzlicher Bedeutung, so daß hier zunächst näher auf sie eingegangen werden soll, bevor wir uns im zweiten Teil meiner Ausführungen anderen Aspekten der jüngeren stadtreformationsgeschichtlichen Forschung zuwenden.

Die verschiedentlich geäußerte These, daß sich aufgrund spätmittelalterlicher Oligarchisierungstendenzen im städtischen Rat „tendenziell ein obrigkeitliches Selbstverständnis“ entwickelte, so daß der Rat das „Kontrollrecht der Bürgerschaft auszuschalten suchte" ", wird kaum noch bestritten. Diskutiert wird vielmehr weiterhin die Frage, ob und inwiefern sich die im Zusammenspiel von fruhkapitalistischen Entwicklungen und spätmittelalterlicher Krise stärker als zuvor polarisierte Sozialstruktur der Stadt in den sog. Verfassungskonflikten des 15. und 16. Jahrhunderts wiederspiegelt (Dazu, die sozialen Aspekte betonend, Maschke 1974, 20; kritisch dagegen Ehbrecht - wie folgt - und Schilling 1975, 197, sowie Schilling 1981, 140).

Wilfried Ehbrecht hat 1974 zum Begriff der "Sozialstruktur" u. a. mit folgenden Bemerkungen kritisch Stellung bezogen: „In der mittelalterlichen Gesellschaft tritt eine Differenzierung nach Einkommens- und Vermögensgruppen hinter einer Gliederung nach Herrschafts- und Verfassungsbezügen zuruck “ (Ehbrecht 1974 a, 87; vgl. dagegen Ellermeyer 1980). Die Sache wird m. E. dann problematisch, wenn diese Verfassungsbezuge mit dem Hinweis auf die Durchdringung der spätmittelalterlichen und frühneuzeitlichen Gesellschaft durch

4. Zitat in Schilling 1975, 197; s. jetzt auch Schilling 1981, 83-84. - Ähnlich bereits bei Maschke 1959, 465-66, und bei Meuthen (zuletzt: Meuthen 1980, 22-24 und 131-32). Fur die Schweiz, s. Muralt 1930, 357, während Hans Conrad Peyer in seiner nun maßgebenden Darstellung den Beginn der "Aristokratisierung ${ }^{\alpha}$ in schweizerischen Städten erst im 16. Jahrhundert ansetzt (Peyer 1978, 109-112). 
den ständischen ordo-Gedanken funktionalistisch überhöht werden s, so daß sich eine sehr scharfe qualitative Trennung zwischen vorindustrieller und industrieller Gesellschaft ergibt. Obwohl sich diese Sicht auf eine etablierte deutsche und französische historiographische Tradition stutzen kann, und gerade weil sich derart kanonisierte Vorstellungen bisweilen der Reflexion zu entziehen scheinen, gilt es $m$. E. darauf hinzuweisen, daß verschiedene Städte zumindest der Zeit vom 15. bis zum späteren 16. Jahrhundert als dysfunktionales Element sich kaum dieser Sicht subsumieren lassen. Im hier diskutierten Zusammenhang wäre etwa auf den wichtigen Aufsatz von Christopher Friedrichs uber "Capitalism, mobility and class formation in the early modern city " hinzuweisen (Friedrichs 1975). Friedrichs sieht „class formation“ im städtischen Rahmen dort entstehen, wo sich im handwerklichen Bereich die Entwicklung arbeitsteiliger Prozesse abzuzeichnen beginnt. Das bedeutet, daß der Klassenbegriff, wobei nicht zwingend ein dualistischer gemeint ist, im Blick auf das 15. und 16. Jahrhundert eigentlich nur auf oberdeutsche Städte angewendet werden sollte, und auch dann noch Unterschiede in der lokalen Entwicklung zu beachten sind. In Straßburg setzt ein solcher Prozeß bereits um die Mitte des 15. Jahrhunderts, in Nördlingen aber erst um die Mitte des 17. Jahrhunderts ein (dazu jetzt auch Friedrichs 1979). Insofern scheint mir Bradys Forderung durchaus einleuchtend, daß der Historiker bei der Untersuchung der städti-. schen Sozialstruktur des Mittelalters und des 16. Jahrhunderts gleichzeitig mit "estate and class categories“ arbeiten sollte (Brady 1978 2, 33; weiterfuhrend dazu jetzt J. Ellermeyers „erweiterter Schichtbegriff": Ellermeyer 1980) ${ }^{\circ}$.

Wenn sich Verfassungskonflikte in den oberdeutschen Städten des 15. Jahrhunderts, wie Erich Maschke gezeigt hat, mit sozialem Konfliktpotential vermischt haben, so ist meines Erachtens im Anschluß an die Forschungen Scribners und Bradys neu zu überdenken, ob die am Beispiel norddeutscher Städte entwickelte Sicht der städtisch-reformatorischen Auseinandersetzungen als ritualisierte Verfassungskonflikte sich vollumfänglich auf das Geschehen im Suden des Reichs ubertragen läßt (s. Ehbrecht 1974 a, 1974 b, 1978, 1980 a; Schilling 1981, 139-40; vgl. dazu auch Maschke 1974, 14-15)'.

5. Eine derartige Hypostasierung findet sich bereits bei Holbom 1936, wo z. B. die Stellung der stadtisch-reformatorischen Prädikanten so gesehen wird: ${ }_{n}$ He was remote from the daily struggle for social hegemony, his office was functional and reflected a higher unity of human relations for which people most ardently longed“ (Holbom 1936, 336).

6. Zusammenfassende Diskussion jetzt in Ilja Mieck, Hg.: Soziale Schichtung und soziale Mobilităt in der Gesellschaft Alteuropas, ( - Historische Kommission zu Berlin, Informationen, Beiheft 5), Berlin 1984.

7. Gegen eine derartige Übertragung sprechen auch die Überlegungen Olaf Morkes. 
Auch bleibt zu fragen, wie sich diese Auseinandersetzungen, die nach Wilfried Ehbrecht "als Ausdruck legitimen Protestes der Bürgergemeinde“ zu betrachten sind, jeweils in den Augen des städtischen Rates ausgenommen haben, der seine Kirchen- und Religionspolitik gegenüber Kaiser und Reich bzw. gegenüber den Landesherrn zu verantworten hatte. Denn in der "Prävention von Konflikten innerhalb der Stadt und mit den übergeordneten Kräften (Rublack) lag ein wesentliches Motiv für die obrigkeitliche Wahrnehmung sozialer Kontrolle, so z.B. in Esslingen, wo der Rat die reformatorische Bewegung bis 1531 hintanhielt (Rublack 1980 a und 1981), so auch in Speyer, wo die Reformation erst 1540 eingeführt wurde, obwohl im Rat schon lange beträchtliche Sympathien für die Reformation vorhanden gewesen waren (Scribner 1975b), und in Augsburg, wo die Ratsherren den entscheidenden Schritt erst 1534 vollzogen, und zwar solely to maintain their authority ... and prevent popular rebellion of their own citizenry" (Broadhead 1980, 70).

Bernd Moeller hat 1978 betont, daß sich "die Rezeption der neuen Ideen ... vor allem in den Städten ... als ein Prozeß der Verständigung " darstellte, und daß „dem Genossenschaftsmotiv ... eigentlich stets der Charakter des Postulats anhaftet(e) “ (Moeller 1979 a, 27-29). Anton Schindling hat gegenüber Brady in diesem Zusammenhang gefordert: „Ferner wäre stärker einzugehen auf die normative Vorstellung, daß die weltliche Obrigkeit, also auch der Stadtmagistrat, verantwortlich ist für den Gottesdienst und das Seelenheil der Untertanen und damit das Recht und die Pflicht zur Reformation hat" (Schindling 1981, 178). Abgesehen davon, daß hier das Problem des städtischen ius reformandi wohl doch zu einfach gesehen wird, legen die oben exemplarisch genannten Fälle Esslingens, Speyers und Augsburgs nahe, daß dort der Rat zumindest vorübergehend die politischen Normen von Friede und Einigkeit höher setzte als die von Schindling angezogenen religiös-normativen Vorstellungen. Wichtig ist in diesem Zusammenhang die Feststellung Hans-Christoph Rublacks, daß integrative Normen vor allem dann vom städtischen Rat zum Ausdruck gebracht wurden, wenn soziale Mobilität und zunehmende arbeitsteilige Differenzierung die Integrationskraft des städtischen Sozialgefüges bedrohten

Er vermag in Luneburg, Braunschweig und Göttingen keine deutlichen materiellen Krisensymptome auszumachen und hebt deshalb - gegenuber Maschke abschwächend - vor allem die "sozialbildenden" Aspekte der "Reformation als soziale( $r$ ) Bewegung" in den untersuchten Städten hervor (Mörke 1983, 300-306). - Strittig bleibt in der jungeren Forschung, ob Fasnachts- und Karnevalsrituale - die z.T. in W. Ehbrechts Argumentation eingehen - als bloße soziale "Sicherheitsventile" betrachtet werden können. Dazu Burke 1978 und 1981, 192 ff., und Scribner 1977 a.

8. Hans-Christoph Rublack: Political and social norms in urban communities in the Holy Roman Empire, in: P. Blickle, H.-C. Rublack und W. Schulze: Religion, Politics and 
Diese Erörterungen zeigen m.E., daß der Appell an die Gemeinschaft in deutschen Städten der Reformationszeit durchaus auch vom Rat als Herrschaftsinstrument eingesetzt werden konnte. Es ist dann auch kein Widerspruch, wenn in einer Situation, in der der Legitimationsdruck (zum Begriff: Blickle 1975 a, 137) stark abnimmt, wie in Straßburg während der Krise von 1547/48, derselbe Appell von Teilen der Gemeinde gegen den Rat gerichtet wird (Brady 1978 a, 16 und 20). Der Begriff des „legitimen Protestes“ (Ehbrecht) allein vermag die Funktion des Legitimationsdrucks, dem reformatorische Bewegungen ausgesetzt sein konnten, nicht zu erklären. Vielfach wurde dabei vom städtischen Rat der Legitimationsdruck "nach unten“ weitergereicht, dem die städtische Obrigkeit selbst seitens des Kaisers und des Reichs oder des Landesherrn ausgesetzt war. Die sog. integrative Betrachtungsweise der Stadt der frühen Reformationszeit tendiert aufgrund ihrer starken Betonung des innerstädtisch-genossenschaftlichen Konsenses zur Vernachlässigung der „auBenpolitischen“ Elemente städtisch-obrigkeitlicher Reformationspolitik. Eine wichtige Ausnahme stellen allerdings in dieser Hinsicht die Forschungen Heinz Schillings dar (zuletzt: Schilling 1981). Schilling betont auch, daß am Vorabend der Reformation der herrschaftliche Aspekt städtischen Verfassungslebens gegenüber dem genossenschaftlichen „zunehmend zur Geltung " kam (Schilling 1981, 84). Strittig bleibt dabei freilich auch weiterhin die Frage der sozialen Dimensionen städtischer Herrschaftsausübung vor und in der Reformationszeit.

Wenn wir uns nun den religiös-sozialen Aspekten der zur Debatte stehenden Forschungskontroverse zuwenden, so können komplexe Sachverhalte der Kürze halber zum Teil nur angedeutet werden.

Die oben zusammengefaßte Kritik an Bradys angeblicher soziologischer Reduktion religiöser Sachverhalte ist $\mathrm{m}$. E. in weiten Teilen eine "question mal posée“, wenn man in Rechnung stellt, daß Brady deutlich hervorhebt, er möchte eine Untersuchung der politischen Aspekte der Straßburger Reformation vorlegen, ohne dadurch den grundlegenden Stellenwert des Theologischen in der deutschen Reformation in Frage stellen zu wollen ${ }^{9}$. Umgekehrt sind wohl

Social Protest. Three studies on early modern Germany, hg. von $K$. von Greyerz, London 1984. Vgl. ergänzend dazu auch Mörke 1983, 295-96.

9. Brady 1978 a, 46 und 198. - Auf den von Moeller 1980 a, 111, als "geheimnisvoll" bezeichneten Satz Bradys („The leading ideas of Reformation Germany were chiefly theological ideas, without a firm grasp of which the culture and self-consciousness of the age simply cannot be understood" - Brady 1978 a, 46) folgt der von Moeller nicht mitzitierte Satz: "That they play a relatively minor role in this study is due rather to the specific aims of the work than to an ignorance of their significance." 
kaum größere Entrüstungsstürme darüber zu erwarten, daß sich René Bornert (Bornert 1981) in seiner vor kurzem erschienenen, umfangreichen und wichtigen Untersuchung zur Straßburger Reformation überwiegend auf deren theologische Aspekte konzentriert.

Die Diskussion der hier auftauchenden Fragen wird dadurch erschwert, daß, nicht nur unter Sozialhistorikern, sondern zuweilen auch unter Kirchenhistorikern, sich eine gewisse Unsicherheit ausbreitet, wenn es um die Historizität des Religiösen geht. So weist Gerhard Müller zurecht darauf hin: "Glaube als persönliche Überzeugung läßt sich bekanntlich nicht messen. Nur Glaubensäußerungen sind feststellbar, aber diese müssen auf dem Hintergrund der historischen Bedingungen interpretiert werden. Denn sie sind von ihrem ,Sitz im Leben', von lokalen, politischen, sozialen und möglicherweise auch persönlichen Voraussetzungen bedingt " (Müller 1981,5). Weiter unten aber wird der hier angesprochenen Religion eine gewissermaßen metahistorische Qualität attestiert, wenn Hans Baron vorgeworfen wird (Baron 1937), er räume religiösen Vorstellungen zwar den ersten Rang ein, halte aber die historischen Gegebenheiten für wesentlich bei der Beurteilung reformatorischer Vorgänge (Müller 1981, 8). Dagegen spricht der des Reduktionismus ziemlich unverdächtige Steven Ozment einmal sogar von "religious and most other social change" $(\mathrm{Oz}$ ment 1975, 10). Auf Richard van Dülmens wohl eher abwegige Vorstellung einer von der Last der Hermeneutik befreiten Sozialgeschichte der Religion kann hier nur kurz hingewiesen werden (Dülmen 1980, 36). Demgegenüber schreibt Heinz Schilling in "Konfessionskonflikt und Staatsbildung“, einem wichtigen Buch, auf das noch zurückzukommen ist: „Unbeschadet ihrer eigenständigen, unabgeleiteten Qualität erscheinen die religiosen und kirchengeschichtlichen Entwicklungen eingelagert in einen übergreifenden gesellschaftsgeschichtlichen Prozeß ${ }^{\mu}$ (Schilling 1981, 365); und weiter: „Die Untersuchung ist insgesamt der funktionalen Methode gefolgt und hat die Frage nach der Qualität des Religiösen und der Konfessionen ... bewußt ausgeklammert" (Schilling 1981, 387). Im an und für sich verständlichen Bemühen, soziale Reduktionismen zu vermei-

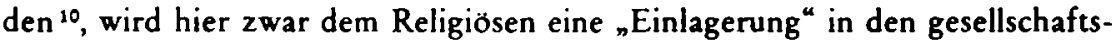
geschichtlichen Prozeß zugestanden, andererseits aber erscheinen seine Ursprünge, wie auch seine Veränderbarkeit, als etwas diesem Prozeß gänzlich Entrücktes. Eine solche Sicht hat natürlich tiefgreifende interpretatorische Konsequenzen. Dazu Schilling 1981, 141: „Es entspricht dieser Interpretation der Reformation als Teil der gemeindlich-genossenschaftlichen Tradition des

10. Dazu: $K$. von Greyerz: Introduction, in: ders., $\mathrm{Hg}$.: Religion and Society in Early Modern Europe, 1500-1800, London 1984. 
Stadtbürgertums, daß die an den religiösen Kern ankristallisierten sozialen und politischen Momente nicht revolutionär, sondern eher restaurativ waren."

Hier stoßen wir auf ein grundsätzliches Verständigungsproblem, das durch Schillings als "gesellschaftsgeschichtlich" verstandene Kritik an Rainer Wohlfeils „sozialgeschichtlicher“ Orientierung verdeutlicht wird: „Anders als der im folgenden entwickelte Ansatz versteht er [d.h. Wohlfeil 1975] das konfessionelle Element aber nicht als zentrale Kategorie, sondern additiv als ein,wesentliches Bestimmungselement sozialgeschichtlicher Betrachtungsweise" (Schilling 1981, 15, Anm.1) ${ }^{11}$. Was hier anklingt, ist die in anderer Hinsicht durchaus fruchtbare Max-Weber-Rezeption „bielefeldscher Prägung“ (vgl. dazu etwa: Kocka 1977). In Anlehnung an Webers Sicht der sog. Rationalisierung wird im Rahmen dieser Rezeption im allgemeinen unterstellt, ein Grundzug der modernen Industriegesellschaft des 19. und 20. Jahrhunderts sei die sog. Säkularisierung. Weitgehend gestützt wird diese letztere Annahme durch die deutsche Religionssoziologie, da diese sich bis vor kurzem - letztlich ausgehend von der Marxschen Religionskritik (dazu: Bosse 1970, 8-20) - nahezu ausschließlich mit Kirchen- und Pfarrsoziologie beschäftigt hat. Heute ist dieses Verständnis industriegesellschaftlicher Säkularisierung keineswegs mehr unumstritten (Rendtorff 1966; McLeod 1981; Schieder 1982), erfreut sich aber weiterhin verbreiteter Zustimmung, die freilich die Gefahr in sich birgt, daß unter evolutionistischen Gesichtspunkten im Blick auf die frühe Neuzeit die Rolle der Religion - gewissermaßen im Gegenzug - funktional überhöht wird (deutlich bei Kocka 1977, 103).

Es sei hier die Frage erlaubt, ob sich im Rahmen der hier zur Diskussion stehenden Forschungsaufgaben nicht allein aus der funktionalen Reduktion des Religiösen, sondern eben auch aus dessen Hypostasierung schwerwiegende Probleme ergeben. Denn wenn im hermeneutischen Vorgriff das Religiös-Sakrale derart zentral gesetzt wird, daß es auch nicht mehr dem Versuch historischer Erklärung zugänglich ist, dann besteht die Gefahr, daß dem Moellerschen Interpretament, dem sich Schilling verpflichtet, ein wesentlicher Teil seiner Verifizierbarkeit entzogen wird. Gerade aber die einzelnen Inhalte dieses Interpretaments bedürften weiterhin, wie dies Hans-Christoph Rublack bereits 1978 gefordert hat, der genaueren Bestimmung.

11. Zum Verständnis dieses Zitats muß hinzugefügt werden, daß in Schilling 1981 eine Neigung vorherrscht, die Begriffe „Kirche“, „Religion“ und „Konfession“ gleichzusetzen. 


\section{UNTERSUCHUNGEN ZUM THEMENKREIS "STADT UND REFORMATION“ (1976-83). \\ VERSUCH EINES SYSTEMATISCHEN KOMMENTARS}

Seit 1976 hat die Erforschung der Stadtreformation nicht nur in vielen Bereichen eine Vertiefung erfahren, sondern auch eine zeitliche und räumlich-geographische Ausweitung. Auf einige der mir dabei wichtig scheinenden Aspekte möchte ich nun im zweiten Teil meines Berichts eingehen.

1. Im Rahmen des gängig mit dem etwas engen Begriff ${ }_{n}$ Stadt und Kirche im Mittelalter" bezeichneten Themenbereichs hat unter den vor 1976 erschienenen Veröffentlichungen die Arbeit Rolf Kießlings zu Augsburg immer noch Vorbildcharakter, zumal Kießling im Gegensatz zur älteren Forschung auch der Frage nachgeht, "welche Gruppen und Schichten sich von den einzelnen religiösen Lebensformen und Aktivitäten angesprochen fühlten " (Kießling 1971, 19). Das Interesse der jüngeren Forschung an dieser Fragestellung wird deutlich im Diskussionsteil des von Jürgen Sydow 1980 herausgegebenen Bandes zum Thema ${ }_{n}$ Bürgerschaft und Kirche" ${ }^{12}$.

Im Vordergrund steht bei fast allen älteren Arbeiten sowie in der seit 1976 erschienenen Monographie Karl Trüdingers zu Würzburg (Trüdinger 1978) und in den Untersuchungen Dieter Demandts zu Kitzingen (Demandt 1978) und Colmar (Demandt 1980) das Verhältnis zwischen Rat und Kirche ${ }^{13}$. Wolfram Heitzenröders Arbeit zum Verhältnis von Reichsstadt und Kirche in der Wetterau ist ausschließlich diesen Aspekten gewidmet (Heitzenröder 1982). Dabei geht es zumeist um Fragen wie die der städtischen Kontrolle des Liegenschaftsmarktes, der Eindämmung der wirtschaftlichen Konkurrenz des Klerus, der Konflikte einerseits um das geistliche privilegium fori (vor allem in Zinsund Ehesachen), andererseits um das privilegium immunitatis (vor allem in Angelegenheiten die geistliche Steuer- und Abgabenfreiheit betreffend) sowie um die Frage städtischen Einflusses auf kirchliche Patronatsrechte.

Daß aber der Schwerpunkt der spätmittelalterlichen Konflikte zwischen Klerus und Laien nicht bei allen Städten im Verhältnis von Rat und Kirche zu suchen ist, hat jüngst wieder Hans-Christoph Rublack mit Blick auf Nördlingen bestätigt. Hauptkonfliktgegenstand war hier die mangelhafte Versorgung der

12. Sydow $1980 \mathrm{~b}$. Vgl. insbesondere die Diskussion des Beitrags von J. Sydow (Sydow 1980 a), ebda., 156-61. - Sydow 1980 a, 10, Anm. 4, enthält einen knappen bibliographischen Uberblick uber Forschungen jüngeren Datums zum hier betrachteten Themenbereich.

13. Ein Teilaspekt dieses Themas wird in bezug auf Numberg, Straßburg und Frankfurt am Main dargestellt in Schindling 1980. 
Bevölkerung durch die Geistlichen (Rublack 1982, 62-63). Die antiklerikale Stimmungslage, die sich aus derartigen Gravamina ergeben konnte, hat Francis Rapp in einer sorgfältigen Arbeit zur Vorreformationszeit in Stadt und Diözese Straßburg untersucht. Er stieß dabei sogar auf einen am Vorabend der Reformation weit verbreiteten „Pfaffenhaß“ (Rapp 1974; dazu Schindling 1981, 171-75). Auch Dietrich Kurze (Kurze 1976, 301) spricht verallgemeinernd von einer „permanente(n) und tägliche(n) Spannung zwischen dem Niederklerus auf der einen Seite und den ihr soziales Bezugsfeld bildenden Laien auf der anderen Seite". Es bleibt zu hoffen, daß Rapps wichtige Studie zu weiteren Untersuchungen gerade des städtischen Bereichs, der bei Rapp etwas zu kurz kommt (Landstädte!), anregen wird ${ }^{14}$. Auch fehlen für diesen Bereich bisher ausführlichere Arbeiten zur wirtschaftlichen Rolle der Welt- und Ordensgeistlichkeit, der städtischen Stifte und Klöster (dazu Scribner 1982 a).

Die Forschung der letzten beiden Jahrzehnte (dazu auch Molitor 1976) hat weitgehend Bernd Moellers Befund einer Intensivierung der Frömmigkeit der Laien um 1500 (Moeller 1965) bestätigt (z. B. Endriß 1967, 174-79; Schlemmer 1975 aus liturgiegeschichtlicher Sicht; und Zmyslony 1977). Dabei dominierte meist - letztlich auch bei Schlemmer 1980 - das Deskriptive bzw. die institutionsgeschichtliche Festschreibung des Themas. Ein dringendes Desiderat, worauf Jürgen Sydow jüngst mit Nachdruck hingewiesen hat (Sydow 1980a, 10). blieb dabei unerfüllt, nämlich die Erforschung der Religion der städtischen Laien ihrem Inhalt nach, denn nur auf dieser Grundlage wird die inhaltliche Rezeption der reformatorischen Lehre genauer als bisher untersucht werden können. Hierzu müßten vor allem auch die sog. volkskundlichen Quellen für den städtischen Bereich systematisch aufgearbeitet werden. Wie zur Frage der Rezeption der reformatorischen Lehren noch zu zeigen sein wird, kann solchen stärker in den mentalitätsgeschichtlichen Bereich vordringenden Untersuchungen nur ein voller Erfolg beschieden sein, wenn ihnen die heuristische Unterscheidung der Begriffe "Kirche“ und „Religion“ zugrundegelegt wird. Auch wird in diesem Zusammenhang der von Hartmut Boockmann aufgeworfenen Frage der Kontinuität häretischer Gruppen in deutschen Städten des Spätmittelalters im Einzelnen weiter nachzugehen sein (Boockmann 1975, 22-24; vgl. dazu auch Trüdinger 1978, 140-44, und Russell 1983).

2. Die Forschung der letzten Jahre hat sich vermehrt auch begrifflichen Problemen zugewandt. Dies gilt insbesondere für den Begriff der "Bewegung“ (dazu Rublack 1978 c, 3, Anm. 1). Der Begriff der „evangelischen Bewegung“

14. Demnächst dazu: Franziska Conrad: Reformation in der bäuerlichen Gesellschaft. Zur Rezeption reformatorischer Theologie im Elsaß, VIEG Bd. 116, Wiesbaden 1984. 
wird zum Beispiel von Ernst Walter Zeeden und Ernst-Wilhelm Kohls (Zeeden 1964; Kohls 1967) verwendet. Kohls unterscheidet scharf zwischen „evangelischer Bewegung“ und „politischer Reformation“, wobei letztere Bezeichnung ausschließlich auf das in den 1520er Jahren einsetzende städtisch-obrigkeitliche Kirchenregiment angewandt wird. "Evangelische Bewegung" und „politische Reformation" überlappen sich zeitlich als Phasen städtischer Reformation.

Dagegen ist kürzlich Rainer Wohlfeil von einer zeitlichen Phasenfolge von "reformatorischen Bewegungen" in der Zeit von 1521 bis 1525 und den "Anfänge(n) obrigkeitsgelenkter evangelischer Reformation" (1525-1529) ausgegangen (Wohlfeil 1982, 23 und 27). Als idealtypische Konstruktion ist dieses zeitliche Raster freilich wenig befriedigend, da reformatorische Bewegungen in verschiedenen Städten überhaupt erst zu einem späteren Zeitpunkt auftreten. Völlig zu Recht wird dagegen von Wohlfeil der Begriff der „evangelischen Bewegung ${ }^{\prime \prime}$ der Kritik unterzogen (Wohlfeil 1982, 96-97) ${ }^{15}$. Als nützlich hat sich andererseits die von Hans-Christoph Rublack eingeführte Unterscheidung von „evangelischen Bewegungen“ im ersten Reformationsjahrzehnt und städtischen „protestantischen Bewegungen“ der zweiten Hälfte des 16. Jahrhunderts erwiesen (Rublack 1978 b und 1978 c), wenngleich im Lichte der jüngeren definitorischen Bemühungen Bob Scribners weiterhin zu diskutieren bleibt, ob sich der Begriff "Bewegung“ auf alle protestantischen Erscheinungen, die in der zweiten Hälfte des 16. Jahrhunderts in Städten mit "Spätreformationen “ bzw. ngescheiterten Reformationen “ zutage traten, anwenden läßt (vgl. Greyerz 1980; Rublack 1978 c). Bob Scribners 1978 vorgelegter Versuch, den Begriff der reformatorischen Bewegung zu instrumentalisieren als kollektive Aktion, im Rahmen derer auf nicht-institutionellem Wege voller Ungeduld eine Veränderung der bestehenden, insbesondere der kirchlichen Ordnung, angestrebt wird, hat vor allem durch Rainer Wohlfeil und - weniger überzeugend - auch durch Gerhard Muller modifizierende Kritik erfahren (Scribner 1979b; Wohlfeil 1982, 99-102; Müller 1981, 16).

Neben dem Begriff der „Bewegung“ ist jüngst auch die Kategorie des „Konflikts “ einer analytischen Präzisierung zuteil geworden. Zu Recht werden dabei die Begriffe ${ }_{n} K_{0}$ onflikt und "Unruhe ${ }^{4}$ von Olaf Mörke "Aufruhr" und "Auf-

15. Wohlfeil 1982, 96-97: „Eine deskriptiv aufgefaßte, rein evangelische, $d$. h. nur auf Reform von Glauben und Kirche auf der Grundlage individueller Gewissensentscheidung nach dem Maßstab des Evangeliums ausgerichtete Bewegung konnte es in dieser Zeit noch nicht geben, denn das überlieferte Verhalten der Christen in und gegenuber der Kirche trennte das religiös-kirchliche noch nicht von politisch-sozialem Handeln, sondern begriff es als gegen- und wechselseitig bedingt." - Kritisch zum Begriff der "evangelischen Bewegung auch: Greyerz 1980, 4-5. 
stand“ gegenüber übergeordnet angesiedelt, da sie „ein breiteres Erscheinungsspektrum abdecken“. Aufgrund dieses Vorverständnisses definiert Mörke „Konflikt“ als „jede Form von öffentlich bewußtem, interessierendem und in soziale Handlung umzusetzendem Interessengegensatz zwischen Einzelnen oder Gruppen ..., den man institutionell und/oder außerinstitutionell zu lösen versucht“. Unter Unruhe versteht Mörke dagegen „die Form des außerinstitutionellen Lösungsversuchs"; „Aufruhr“ und „Aufstand“ sind demnach, in bezug auf Gewaltandrohung und -anwendung, als besonders intensive „Erscheinungen von Unruhe“ zu verstehen (Mörke 1982, 148). Mörkes Anwendung der derart festgelegten Kategorien auf die innerstädtischen Konflikte in Braunschweig 1374-1386 und um 1528/29 überzeugt, wird sich aber erst noch in weiteren Untersuchungen zu bewähren haben (dazu jetzt auch: Mörke 1983).

Als Grundlage für solche Untersuchungen bieten sich an die neuerdings in der Zahl zunehmenden Arbeiten zur Sozialstruktur deutscher und schweizerischer Städte des 15. und 16. Jahrhunderts und zu deren Führungsschichten (zusammenfassend: Press 1980 b; Endres 1980). Hier ist zunächst auf die aus dem Sonderforschungsbereich "Spätmittelalter und Reformation" hervorgegangenen Untersuchungen vor allem zur fränkischen Landstadt Kitzingen hinzuweisen (zuletzt: Bátori/Weyrauch 1982, dort Hinweis auf frühere Publikationen). Die Tübinger Gruppe hat insbesondere im Bereich quantitativer Analyse städtischer Steuerbücher Grundlagenarbeit geleistet, woraus eine Reihe wichtiger theoretischer Abhandlungen resultierte (etwa: Bátori 1975; Weyrauch 1976 und 1980; Rublack 1979). Für den nord- und nordwestdeutschen Bereich sind zu erwähnen die Untersuchungen Klaus-Joachim Lorenzen-Schmidts (zuletzt: Lorenzen-Schmidt 1980) und Heinrich Rüthings, der in einer allerdings sehr kurzen Studie zu den sog. "Nicht-Partizipierenden“ Höxters demonstriert, daß auch eine spärliche Quellenbasis Aussagen zur städtischen Sozialstruktur erlauben kann (Rüthing 1982). Gingen die erwähnten Tübinger Untersuchungen weitgehend von Steuerbüchern als Quellengrundlage aus, so hat Hans Füglister vor kurzem in einer materialreichen und vorzüglichen Arbeit zur sozialen bzw. sozialtopographischen und politischen Struktur Basels in der ersten Hälfte des 16. Jahrhunderts in Zunftakten eine für diesen Forschungsbereich relativ neue Quellengattung systematisch erschlossen (Füglister 1981).

$\mathrm{Zu}$ den Führungsschichten nordwestdeutscher Städte des 16. Jahrhunderts hat Heinz Schilling 1979 eine Übersichtsdarstellung vorgelegt (Schilling 1979), die er vor kurzem auf breiter Basis und unter Verlagerung der zeitlichen Perspektive ins spätere 16. und 17. Jahrhundert weitergeführt hat (Schilling 1983 a). Ergänzend muß dazu der aus dem Münsterer Sonderforschungsbereich "Stadt und Kirche im Mittelalter und in der werdenden Neuzeit" hervor- 
gegangene Sammelband zu den städtischen Führungsgruppen Nord- und Nordwestdeutschlands (Ehbrecht 1980 b) hinzugezogen werden, dessen thematischer Schwerpunkt allerdings eher im 15. Jahrhundert liegt.

Wenn nach Scribner "Reformation ${ }^{*}$ nicht als "Addition individueller Entscheidungen", sondern als eine "Form kollektiven Verhaltens“, d.h. eben als "Bewegung" betrachtet werden sollte (Scribner 1978, 57), so ist sicher der ergänzende Einwand Wohlfeils zu berücksichtigen, daß diese Sicht „uns nicht von der Aufgabe [entbindet], die Haltung des Individuums in seiner Gruppe oder das Auftreten eines einzelnen als ihr Exponent zu analysieren" (Wohlfeil 1982, 100-101; dazu auch Lutz 1979, 23), um so mehr als Scribner a.a.O. den hier anklingenden behaviouristischen Ansatz ablehnt (Scribner 1981, 95). Dies gilt zunächst vor allem für die Initiatoren dieser Bewegungen. In der Frühzeit der Reformation waren dies in erster Linie Geistliche ${ }^{16}$. Als Predigern und auch als Autoren von Flugschriften fiel ihnen eine kaum zu unterschätzende Rolle in der Frühphase der Reformation zu. Erneut ist in diesem Zusammenhang mit Nachdruck auf den humanistischen Background insbesondere der oberdeutschen Reformatoren hingewiesen worden (Kittelson 1976; vgl. auch Spitz 1975, $401 \mathrm{ff}$.) sowie auf die enge Verzahnung der spätmittelalterlichen via-antiqua Tradition mit der oberdeutschen und schweizerischen Stadtreformation, deren Initiatoren sich darin von den hauptsächlich aus der via moderna hervorgegangenen Reformatoren Mittel- und Norddeutschlands unterschieden (Oberman 1977, 362 ff.).

Auf neuere Arbeiten zur Rolle bürgerlicher Multiplikatoren und Träger der Reformation, die sich des Anliegens der Reformatoren angenommen und dieses weiter verbreitet haben, kann nur sehr selektiv hingewiesen werden. Neben dem Lubecker Jürgen Wullenwever (Korell 1980) hat vor allem der Straßburger Stettmeister Jakob Sturm als einflußreicher städtischer Exponent der oberdeutschen Reformation erneut die Aufmerksamkeit der Forschung auf sich gezogen

16. Es wurde hier zu weit fuhren, auf Einzeluntersuchungen zu solchen „Initiatoren“ einzugehen (knapper Uberblick bei Wohlfeil 1982, 103-104); es sei daher auf den Literaturbericht des ARG verwiesen. Hingewiesen sei hier lediglich auf die Untersuchung von Justus Maurer, Prediger im Bauernkrieg (Maurer 1979), die auch den städtischen Bereich beruhrt. Noch fehlt für die städtische Reformation eine ahnlich umfassende sozialgeschichtliche Untersuchung, wie sie Bernhard Vogler (Vogler, B. 1976) fur den pfallzisch-mittelrheinischen Raum vorgelegt hat. Ein wichtiger Beitrag zur Schließung dieser Forschungslucke leistet Scribner 1980. Seine prosopographische Untersuchung von 176 evangelischen Prädikanten der Zeit vor 1550 zeigt, daß der Großteil dieser Prediger aus Stadten stammte, sich häufig aus der städtischen Oberschicht rekrutierte und meist dem katholischen Klerus der Vorreformationszeit angehort hatte. - Vgl. auch LorenzenSchmidt 1978. 
(Livet 1977; Rott 1977; Pariset 1977). Die Rolle der Stadtschreiber als Multiplikatoren wird durch neue Untersuchungen etwa zu Lazarus Spengler von Nürnberg (Grimm 1978; auch Ozment 1975, 74-79; und Rott, 1972) und zu Jörg Vögeli von Konstanz (Hamm 1978; Seebass 1978 b; auch Ozment 1975, 79-83) erneut betont. Eine Reihe von Beiträgen jüngeren Datums sind der faszinierenden Figur des bernischen Malers, Schriftstellers und Reformationspolitikers, Niklaus Manuel, gewidmet worden (s. Historischer Verein ... 1980). Darüber hinaus ist im Rahmen der neuerdings außerordentlich expansiven Flugschriftenforschung (s. dazu unten) auf bisher weniger bekannte Laien als frühe Förderer reformatorischer Bewegungen hingewiesen worden (vgl. etwa Chrisman 1980, ergänzend dazu Rott/Koch 1978 und Lienhardt 1980; auch Russell 1983).

Verstärkt hat sich das Interesse der Forschung in den letzten zehn Jahren für den Anteil der Frauen an reformatorischen Bewegungen bzw. für die Auswirkungen der Reformation auf die wirtschaftliche und soziale Stellung der Frau. Noch befindet sich jedoch die wissenschaftliche Thematisierung dieser Fragen in ihren Anfängen (zusammenfassend: Wohlfeil 1982, 105-106 und Irwin 1982). Während bei Roland Bainton (Bainton 1974) noch die Konzentration auf einzelne markante Frauengestalten überwiegt (das thematisch wichtige $\mathrm{Ka}$ pitel "Women of the Anabaptists" wirkt beinahe ein wenig wie ein Fremdkörper), so widmet sich bereits Miriam U. Chrisman demselben Thema auf wesentlich breiterer Basis (Chrisman 1972). Während sich sowohl Bainton - soweit er den städtischen Rahmen berührt - wie Chrisman auf Straßburger Frauen der Reformationszeit konzentrieren, so sind demnächst zu Augsburg stärker struktur- und sozialgeschichtlich orientierte Untersuchungen Lyndal Ropers zu erwarten ${ }^{17}$. Methodisch ähnlich ausgerichtet ist eine soeben von Susan KarantNunn zu Zwickau vorgelegte Studie. Zu Recht weist Karant-Nunn u.a. auf die wichtige Rolle von Frauen in den städtischen evangelisch-radikalen Bewegungen des frühen 16. Jahrhunderts hin (Karant-Nunn 1982, 37-41). Dieses bereits von Bainton für das Täufertum aufgegriffene Thema würde für die Städte eine Untersuchung auf breiterer Basis verdienen (zu Straßburg jetzt auch: Deppermann 1979, 178-186). Dasselbe gilt für die Rolle, die Frauen in den innerstädtischen Konflikten der Jahre 1524-26 spielten. Auch wird weiter der Frage nachzugehen sein, ob die Reformation in der Tat die Frau aus der gewerblichen Be-

17. Lesenswert ist Lyndal Ropers umsichtige Studie zu den religiösen und sozialen Aspekten der Eheschließung im Augsburg des 16.Jahrhunderts: Going to church and street. Weddings in sixteenth century Augsburg, erscheint in: Past and Present, 106, Febr. 1985. Vgl. auch L. Roper: Prostitution in sixteenth century Augsburg, erscheint in: History Workshop Journal, 19, 1985. 
rufstatigkeit „in den ihr nach Ansicht der Reformatoren zustehenden Raum, nämlich Haus und Familie verwiesen " hat (Händler-Lachmann 1980, 174 - dort ausdrücklich als Frage formuliert). Kurt Wesoly betont vor allem die wirtschaftlichen Schwierigkeiten, die diesen Vorgang ausgelöst hätten (Wesoly 1980. 89). Heben noch Edith Ennen (Ennen 1980) - sehr knapp - und insbesondere Barbara Händler-Lachmann aufgrund älterer Literatur die eigenständige Rolle der Frau im städtischen Erwerbsleben des Spätmittelalters hervor, so zeigt sich Wesoly aufgrund einer sorgfältigen quellenkritischen Untersuchung in dieser Beziehung sehr skeptisch. Seine Skepsis findet Bestätigung in einer vor allem die unterprivilegierte Lage von Witwen und alleinstehenden Frauen der Stadtgesellschaft Schleswigs und Holsteins hervorhebenden quantitativen Untersuchung (Lorentzen-Schmidt 1979) ${ }^{18}$. Auf Steven Ozments Untersuchung zum Familienleben der Reformationszeit (Ozment 1983) kann hier nur ganz am Rande hingewiesen werden, da sie weit über den Rahmen von „Stadt und Reformation“ hinausführt. In kritischer Distanz zu neueren familiengeschichtlichen Forschungen (u.a. von Ph.Ariès, J.-L. Flandrin und L. Stone) zeichnet Ozment ein ausgesprochen ansprechendes Bild des Familienlebens im 16. Jahrhundert als einer reformatorischen Errungenschaft. Seine Kritik der erw. Forschungen beruht auf der impliziten Annahme der Vergleichbarkeit der englischen, französischen und mitteleuropäischen sowie städtischer und ländlicher Verhältnisse. Ob diese Annahme richtig ist, wird erst noch näher abzuklären sein. Es überrascht, daß Ozment in seiner Darstellung uber weite Strecken auf die autobiographischen Aufzeichnungen des altgläubigen Kölner Patriziers Hermann von Weinsberg zurückgreift.

3. Wie vollzog sich die Rezeption der reformatorischen Lehre durch die städtischen reformatorischen Bewegungen?

Auf die Bedeutung des Antiklerikalismus als einer wesentlichen Triebkraft der deutschen Reformation haben zuletzt Henry Cohn und Hans-Jurgen Goertz hingewiesen (Cohn 1979a und 1979b; Goertz 1982). In Anlehnung an Cohn und zusammenfassende Bemerkungen Rainer Wohlfeils (Wohlfeil 1982, 16) lassen sich folgende Aspekte herausstellen:

a) Kritik am sittlichen Fehlverhalten und an seelsorgerlicher Nachlässigkeit des Klerus - jüngst erneut etwa für Hamburg (Postel 1980 a) und Nördlingen (Rublack 1982, 62-63) betont.

18. Dagegen hebt Merry Wiesner Wood auf mehr deskriptiver Grundlage die herausragende Rolle von Frauen im Verteilungs- und Dienstleistungssektor der Nürnberger Wirtschaft des 16.Jahrhunderts hervor: „One might almost say that women form a subeconomy in early modern Nuremberg, responsible for local trade, and very aware of the needs and requirements of the local market" (Wood 1981, 3). 
b) Wirtschaftlich begründeter Neid und auch $\mathrm{Haß}$ gegenüber dem privilegierten Klerus - insbesondere von Francis Rapp hervorgehoben (Rapp 1974).

c) Der sog. „antirömische Affekt“, der sich vor allem an den finanziellen Forderungen der päpstlichen Kurie entzündete - ein Element, das auf die Breitenwirkung humanistisch-nationaler Gedanken hindeutet, wenn auch diese Breitenwirkung noch genauerer Untersuchungen bedarf (dazu: Dickens 1979, 15-18).

d) Inwiefern sich bereits vorreformatorischer Antiklerikalismus auch „aus häretischem Bezweifeln" einer Notwendigkeit der sakramentalen Funktionen des Klerus gespeist hat (s. Wohlfeil 1982,16), ist im Anschluß an die erwähnten Gedankengänge Hartmut Boockmanns (Boockmann 1975, 22-24) noch genauer zu erforschen.

Goertz dagegen zeigt sich gegenüber Differenzierungsversuchen, wie dem hier vorgetragenen, sehr skeptisch und meint, letztlich ließen sich religiöse, politische, soziale und wirtschaftliche Ursachen und Motive des Antiklerikalismus nicht auseinanderdividieren; es könnten nur verschiedene Wirkweisen des Antiklerikalismus unterschieden werden (Goertz 1982, 206-208). Auch lassen sich nach Goertz die Naht- und Verbindungsstellen zwischen antiklerikaler Grundstimmung und der Rezeption reformatorischer Lehre nicht genau bestimmen: „Sicherlich war der Antiklerikalismus ein Nährboden für die Reform, aber grundsätzlich war er wohl, durch reformatorische Schriften und Predigten belebt und geschärft, die Form, in der die Reformation aufgenommen wurde. Für die Bauern waren Antiklerikalismus und Reformation identisch" (Goertz 1982, 199-200). M.E. entbindet dies aber nicht von der Aufgabe, die Verbindungen, die der Antiklerikalismus jeweils mit reformatorischen Lehren einging, inhaltlich zu untersuchen. Freilich können solche Verbindungen nur im lokalen und ev. im regionalen Rahmen genauer bestimmt werden. So entbehren z. B. gewisse städtische Klosterstürme der Jahre 1524/25 einer entschieden religiösen Motivation (s. z. B. Rublack 1978 d, 70-71). Andererseits ist es gerade im städtischen Bereich oft zu einer engen Verzahnung von antiklerikalen und reformatorischen Motiven gekommen, zuletzt hervorgehoben von Hans-Christoph Rublack in bezug auf Eßlingen, wo Antiklerikalismus „einen Teil des Eßlinger Nährbodens der Rezeption Luthers" darstellte (Rublack 1981, 75). Weiter diskutiert werden muß die Frage der Kontinuität des vorreformatorischen Antiklerikalismus in den Anfangsjahren der Reformation. Während William S. Stafford mit Blick auf Straßburg betont, die frühe reformatorische Predigt hätte dem alten Antiklerikalismus der Laien bloß eine neue Stoßrichtung verliehen (Stafford 1974 und 1977), so meint Goertz - offenbar ohne Staffords These gänzlich abzulehnen -, „die Reformation habe sich im Antiklerikalismus den 
Boden für ihre Aufnahme und Verbreitung erst selber geschaffen " (Goertz 1982, 206-207).

Ob Antiklerikalismus die sich von Königsberg und Riga bis nach Zürich und Basel ereignenden Bilderstürme der Reformationszeit in gleichem Ausmaß motiviert hat wie die Klosterstürme der 1520 er Jahre ist noch nicht geklärt. Überhaupt bedarf das Phänomen des Bildersiurms dringend eingehender Erforschung (die bisherige Diskussion zusammenfassend Christensen 1982, 251-52). Festhalten läßt sich allerdings bereits jetzt, daß der Einfluß bilderfeindlicher Reformatoren, wie Karlstadt und Zwingli, auf diese Vorgänge sicherlich überschätzt worden ist (s. Garside 1966; Stirn 1977). In diesem Sinne betont etwa Bernd Moeller die "Entsprechung" der reformatorischen Bildersturme Basels und Lübecks „zu der evangelischen Predigt“ (Moeller 1980 b, 21). Neben diesem reformatorischen Einfluß, der sich vor allem auf das Bilderverbot des Alten Testaments berief, spielten - wie die Forschung der letzten Jahre gezeigt hat auch magische Elemente eine motivierende Rolle. So betont z. B. Klaus Deppermann in bezug auf den zweiten Rigaer Bildersturm vom März 1524, es habe sich dabei um einen „Akt der Befreiung des Menschen von der Magie des Bildes" gehandelt (Deppermann 1979, 47). In den niederländischen Bilderstürmen von 1566 verband sich dieses Element, wie Phyllis Mack gezeigt hat (Mack 1979, 192-195; vgl. auch Hörger 1978, 141) mit antiklerikalen Motiven: durch den Akt der Bilderzerstörung wurde symbolisch die vom Volk den Priestern zugeschriebene magische Kraft gebrochen. Wie zum Teil auch in den Fastnachtsritualen der frühen Reformationszeit (s. Scribner 1977 a) verbanden sich hier Aspekte traditioneller Volkskultur mit Antiklerikalismus und vielleicht auch mit bilderfeindlicher, vor allem durch die Predigt vermittelter, reformatorischer Lehre.

$\mathrm{Zu}$ diesen Motiven hinzutreten konnte schließlich auch ein soziales Element, nach Thomas A. Brady (s. oben, Teil I) zuletzt hervorgehoben durch Rainer Wohlfeil (Wohlfeil 1982, 136-138).

Generell hat Bernd Moeller - gerade auch im Zusammenhang mit der Frage der Erklärung des Phänomens der Bildersturme - betont, daß „bei dem Versuch, einen Vorgang wie die städtische Reformation zu deuten, wohl eher sozialanthropologische als soziologische Kategorien angemessen wären“ (Moeller 1979 a, 29). Eine ähnliche Forderung hat seither auch Anton Schindling erhoben (Schindling 1981, 187). Dadurch würde in begrüßenswerter Weise der bisher eher stiefmütterlich behandelte städtische Alltag stärker ins Blickfeld der Forschung geruckt. Zu überlegen wäre dabei freilich, ob diese Aufgabe im Rahmen der bisher vorherrschenden Betrachtungsweise erfült werden kann. In derartige Überlegungen wären beispielsweise die Beobachtungen Hans Fügli- 
sters über die Rolle der Weber in der frühreformatorischen Bewegung Basels einzubeziehen. Er weist u.a. nach, daß dabei keine „integrale(n) reformatorischen Programme“ vorgetragen wurden, "sondern stets nur einzelne Segmente, die sich gerade dadurch auszeichnen, daß sie in Beziehung zur spezifischen Bedürfnisstruktur der Gruppe stehen, die sie trägt “ (Guggisberg/Füglister 1978, 56; dazu jetzt auch, die sozialkritischen Implikationen des Weberprotests hervorhebend: Guggisberg 1982, 28). Was hier gemeint ist, wird noch deutlicher, wenn Hans-Christoph Rublack „den Abstand des alltäglichen Nördlinger Lebens von der hohen Ebene der ,Reformation“" betont (Rublack 1982, 9). Wie übertrieben hoch diese Ebene zuweilen veranschlagt wird, zeigt folgendes Zitat: "In den unruhigen Zeiten vor und nach 1521 hatte jene Bevölkerungsgruppe das geringste offentliche Aufsehen gemacht, die der Zahl nach die bei weitem größte war - die Bauem ... die Bauern selbst kamen kaum irgendwo zu Worte, sie schienen gegenüber der Reformation in der Geschichtslosigkeit ihrer lokalen und naturgebundenen Bezüge zu bleiben, als hätten sie die neuen Lehren überhört - sie hatten ja kaum Anteil an der Bildung“ (Moeller 1977, 90-91). Viel zutreffender ist wohl die von Kurt Maeder in bezug auf die frühen Reformationsjahre Zürichs geäußerte Annahme, „daß mit Ausnahme eines sehr kleinen Kreises von Gebildeten oder durch irgendwelche Umstände frühzeitig mit reformatorischem Gedankengut in Berührung gekommenen Leuten die Verwirrung und Unsicherheit gegenüber den sich widersprechenden : Yeinungen und Behauptungen der ... Geistlichen allgemein war" (Maeder 1973, 16).

Aus sozialgeschichtlicher Perspektive stellt sici. die Frage, ob den sich hier andeutenden Problemen aufgrund einer Betrachtungsweise beizukommen ist, die in ihrem hermeneutischen Vorverständnis implizit dazu neigt, die Kategorien "Kirche“, "Religion" und „Konfession“ ineins zu setzen. Insbesondere die historisch-anthropologisch ausgerichteten Forschungen von Natalie Zemon Davis haben $m$. E. gezeigh, wie weit derartige Untersuchungen, wenn sie sich mit dem Alltag der Reformationszeit beschäftigen, über Studien hinausführen können, die aufgrund einer impliziten begrifflichen Identifizierung von Religion" und "Kirche" primär der Aufgabe gewidmet werden, im Anschluß an die ältere Volkskunde die Grenzlinie zwischen volkstümlichem „Aberglauben " und kirchlich-sakramentaler Religion im vermeintlichen Graben anzusiedeln, der

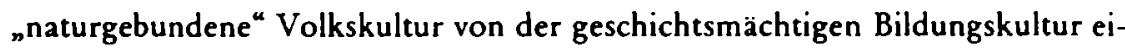
ner gesellschaftlichen Elite zu trennen schien (Davis 1974, v. a. 307-309; vgl. auch Davis 1975). Allgemeiner und zugleich pointiert formuliert: Es ist ein Unterschied, ob wir im Rahmen einer historisch-anthropologischen Betrachtungsweise vom hermeneutischen Vorverständnis einer religiös bestimmten Kultur der fruhen Neuzeit oder im Anschluß etwa an Max Weber und Ernst Troeltsch 
von der Vorstellung einer kirchlich und theologisch bestimmten Kultur dieses Zeitraumes ausgehen ${ }^{19}$.

Dieser Unterschied manifestiert sich recht deutlich auch in der Diskussion der Bedeutung von Flugschriften bei der frühen Verbreitung reformatorischer Lehren in den Städten. Einige wenige Hinweise auf diese wichtige Diskussion müssen hier genügen, zumal sich die Flugschriftenforschung inzwischen als völlig selbständiger Forschungszweig etabliert hat ${ }^{20}$. Aus sozialgeschichtlicher Sicht sei bloß betont, daß die kulturellen Bezugsrahmen des Verfassers einer Flugschrift und des jeweiligen Lesers nicht notwendigerweise identisch sein mußten, so $\mathrm{da} B$ sich beim Leser durchaus ein ${ }_{n}$ divergierender Zugriff auf den Text ${ }^{\text {" }}$ und damit auch ein anderes als das durch den Verfasser intendierte Begreifen dieses Textes ergeben konnte (Wohlfeil 1982, 111). Es ist ein Verdienst Carlo Ginzburgs, diesen Sachverhalt in einem anderen Zusammenhang in anschaulicher Weise verdeutlicht zu haben (Ginzburg 1976 und 1979). Mit Bob Scribners vor kurzem erschienener Studie zu den ikonographischen Aspekten reformatorischer Flugschriftenpropaganda ist eine wichtige, bisher meist ubergangene Dimension der Verbreitung reformatorischer Lehren, systematisch erforscht worden (Scribner 1981). Gerade in dem von Scribner untersuchten Bereich gingen reformatorische Lehren und traditionelle Volkskultur besonders

19. So Troeltsch 1897 zur „Aufklärung“: Sie sei „Beginn ... der eigentlich modernen Periode ... im Gegensatz zu der bis dahin herrschenden kirchlich und theologisch bestimmten Kultur, gegen die sich bereits seit Ausgang des sog. Mittelalters lebhafte Gegenströmungen erhoben hatten, die aber seit Ausbruch der Kirchenspaltung mit verschärftem Nachdruck sich wieder verfestigt hatte" (wieder abgedruckt in $E$. Troeltsch: Gesammelte Schriften, Bd.4, Tubingen 1925, 338; hier zitiert nach Schilling 1981, 24, Anm. 24). Auch bei Max Weber: Die protestantische Ethik und der Geist des Kapitalismus (1905; wieder abgedruckt in: $M$. Weber: Die protestantische Ethik, Bd. 1: Eine Aufsatzsammlung, hg. von Johannes Winckelmann, 5. Aufl., Gütersloh 1979, 27-277), dominieren die theologischen Begrundungszusammenhänge; die empirische Untersuchung der von Weber postulierten Umsetzung von Theologumena in soziales Handeln bleibt immer noch (von sehr wenigen, bis heute vorliegenden lokalen und regionalen Studien abgesehen) ein durch die historische Forschung einzulosendes Desideratum. - Siehe dazu auch Reinhard 1981, 277: „Ausschlaggebend war bisher, daB es sich bei den historisch untersuchten kulturellen Phänomenen um ausgesprochene Elitephänomene handelt, der demo-ökonomische Regelkreis aber in erster Linie das Leben der Massen betrifft. Es käme also darauf an, den Diffusionsprozeß zwischen beiden kulturellen Ebenen zu klăren, um zu einem Gesamtbild der Gesellschaft zu gelangen."

20. Vgl. Moeller 1979 a und Ozment 1979; kritisch dazu Scribner 19792, und Wohlfeil 1982, 124-25. Wichtig für den jungsten Stand dieses Forschungszweiges ist vor allem der kurzlich von H.-J. Kohler herausgegebene Tagungsband (Köhler 1981). Eine knappe Zusammenfassung bietet auch Ozment 1982 a. 
kreative Verbindungen ein. Aus komplementärer Sicht hat auch Miriam U. Chrisman nachgewiesen, wie im Umfeld Straßburgs "lay culture“ und "learned culture" sich im ersten Reformationsjahrzehnt gegenseitig stark angenähert haben, um sich in den folgenden Jahrzehnten wieder zusehends voneinander zu trennen (Chrisman 1982).

Nicht zu Unrecht plädiert A. G. Dickens gegen eine Überschätzung der Rolle des gedruckten Mediums bei der Verbreitung reformatorischer Lehren (nustification by Print Alone ${ }^{4}$ ), wie sie sich in den letzten Jahren bei einzelnen Autoren anzukündigen scheint (s. etwa Moeller $1979 \mathrm{a}, 30$ ), und betont dagegen erneut die Bedeutung der Predigt (Dickens 1979, 22). Gottfried Seebass verweist für Nürnberg auf den wichtigen Prozeß des Ineinandergreifens von Predigt und Flugschriftenpropaganda (Seebass 1978, 71). Auch Gottfried Schramm hebt in bezug auf Danzig, Elbing, Thorn und die deutschen Städte im westlichen Großpolen die Bedeutung des durch die Kirche in den Städten des 15. Jahrhunderts mächtig entwickelten "Instituts der Predigt " hervor, wodurch die Reformation ein "Integrationsmuster übernehmen [konnte], das sie davor bewahrte, wie der Humanismus auf eine Oberschicht beschrärkt zu bleiben oder aber - als ausgesprochene Popularbewegung - gerade die Gebildeten und Besitzenden abzustoßen" (Schramm 1977, 134). Während diese Interpretation im Lichte der oben (Teil I) zusammengefaßten Forschungsdiskussion nicht unproblematisch ist, so scheint mir andererseits Schramms Folgerung, „daß die deutsche Reformation eine von den Kanzeln herunter verbreitete Bewegung war" (Schramm 1977, 136) sehr bedenkenswert. Sicherlich ist die Bedeutung der Predigt kaum hoch genug zu veranschlagen. Für Winfried Becker war sie eine "entscheidend(e) "Voraussetzung der Einführung der Reformation in den Städten (Becker 1983, 87). Andererseits gilt es auch in diesem Zusammenhang nochmals an die oben erwähnte Möglichkeit des „divergierenden Zugriffs“ zu erinnern ${ }^{21}$.

4. Welche reformatorischen Lehren wurden durch die städtischen Bewegungen rezipiert?

Der Unterschied $z$ wischen der niederdeutsch-lutherischen und der oberdeutschen Stadtreformation, die sich zunächst Bucer und Zwingli anschloß, wurde seinerzeit von Bernd Moeller herausgearbeitet (Moeller 1962 und 1964). Heiko

21. Dazu demnächst die noch unveröffentlichte Saarbruckener Dissertation von Franziska Conrad (wie Anm. 14). - Für die Stždte fehlt bisher eine ăhnliche Untersuchung, die sich fur die Frühzeit der Reformation auf eine systematische Analyse innerstädtischer Beschwerdeartikel der zwanziger Jahre des 16. Jahrhunderts stutzen könnte. Ansätze dazu finden sich etwa bei Guggisberg/Füglister 1978, und bei Mörke 1982. 
Oberman hat seither auf die Verbindungen zwischen dieser Unterscheidung und dem spätmittelalterlichen theologischen Wegestreit hingewiesen (Oberman 1977, 362-378).

In zwei ausführlichen Aufsätzen hat Bernd Moeller 1970 und 1974, in Weiterführung seiner früheren Forschungen und ausgehend von einer Untersuchung der Zürcher Disputationen des Jahres 1523, die verschiedenen städtischen Glaubensdisputationen der deutschen und schweizerischen Reformation als Vorgänge interpretiert, die die reformatorischen Kirchen politisch und rechtlich konstituierten. Er schrieb damit diesen Disputationen dieselbe Funktion im städtischen Bereich zu, die in den Territorien den Visitationen zukam (Moeller 1970 und 1974). Während Gottfried W. Locher Moellers Interpretation der Zürcher Vorgänge bestätigt (Locher 1979, 123 ff.), hat Heiko A. Oberman mit Nachdruck die m. E. überzeugende These verfochten, bei der ersten Zürcher Disputation vom 29. Januar 1523 habe es sich nicht um eine Disputation, sondern vielmehr um eine "Gerichtsverhandlung, und zwar in der seit jeher üblichen Form der Konfrontation oder des Verhörs ,gegen einandern““ vor dem Rat als Schiedsrichter gehandelt, und daß dieser Vorgang „deshalb nicht wie bisher als obrigkeitliche Absegnung und Parteinahme für Zwinglis theologisches Programm gedeutet werden [sollte], sondern als Schutz für alle Amtsträger, sofern sie ihre Verkündigung biblisch ausweisen können“ (Oberman 1977, 248-249). Mit Blick auf die gleichzeitigen Vorgänge in Bern wird Obermans These nun auch durch Ernst Walders Interpretation des sog. Jorg Brunner-Handels von 1522 erhärtet (Walder 1980, 502). Dadurch wird Winfried Beckers These von der Einführung der Reformation durch den städtischen Rat als einem "das Mittelalter hinter sich lassenden Paradox" deutlich relativiert (vgl. Becker 1983, 130).

Steht bei Moeller damit das Schriftprinzip im Zentrum seiner Auffassung der Zurcher Vorgänge und derer weiteren Ausstrahlung, so hat Martin Brecht diese Interpretation mit dem Hinweis auf die seines Erachtens gerade auch in der fruhen Reichsstadttheologie Oberdeutschlands vorherrschende Berufung auf Luthers Rechtfertigungslehre angefochten (Brecht 1977). Fur den kritischen Leser nicht nachvollziehbar bleibt dabei aber der Vorgang, durch den sich bei Brecht die theologische Begrundung der von ihm herangezogenen sog. Reformationsvorschläge unter der Hand in das Selbstverständnis der frühen Reichsstadtreformation schlechthin verwandelt (Brecht 1977, 219; dazu kritisch: Greyerz 1980, 5, und Blickle 1982 a, 93, Anm.6). Auch wird durch Brecht nicht erklärt, wie es im oberdeutschen Raum vor allem in bezug auf die Sittenzucht zu besonderen Ausformungen des reformatorischen Kirchenregiments kommen konnte. In diese Diskussion ist nun auch die neuere Darstellung Gottfried 
W. Lochers über die Ausstrahlungen des Zwinglianismus in Oberdeutschland miteinzubeziehen (Locher 1979, 452-501) ${ }^{22}$.

Vor kurzem hat Martin Brecht erneut auf den Stellenwert des „Luthertum(s) als politische und soziale Kraft in den Städten " hingewiesen (Brecht 1980), wobei allerdings die frühere Kritik an Bernd Moellers obigem Interpretament stark zurücktritt. Das mag zum Teil damit zusammenhängen, daß Moeller selbst seither wieder stärker den Einfluß der Wittenberger Reformation auf die gesamte deutsche Stadtreformation hervorgehoben hat (vgl. Moeller 1977 und 1979 a, 27 und 36; dazu auch: Müller 1981, 11 und 36) ${ }^{23}$. Deshalb bestehen heute kaum noch eigentliche Gegensätze zwischen der Position, die Moeller seit 1977 in dieser Frage eingenommen hat, und den zuletzt erwähnten Überlegungen Martin Brechts. Sinngemäß gilt dies auch für den bereits früher von Heinz Schilling gegebenen Hinweis, daß sich im städtischen Luthertum das auf die Zwei-Reiche-Lehre Luthers zurückführbare Obrigkeitsdenken erst allmählich zu realisieren vermochte (Schilling 1975, 235). Neuerdings hat Schilling diesen ProzeB bis ins frühe 17. Jahrhundert hinein weiter verfolgt. Er weist nach, daß nicht nur in Lemgo, sondern auch in Marburg, Amberg, Pforzheim, Siegen, Korbach und Berlin, das städtische Luthertum immer noch so viel Vitalität besaß, daß es sich der durch den Landesherrn verordneten Zweiten Reformation aktiv widersetzte (Schilling 1981, 369-370; zusammenfassend zu den städtischen Unruhen im späten 16. und im frühen 17. Jahrhundert auch Friedrichs 1978, der allerdings zu einseitig auf die genossenschaftlichen Aspekte abhebt).

Über die Tiefen- und Breitenwirkung reformatorischer Lehren innerhalb der städtischen Gesellschaft im AnschluB an die in den dreißiger Jahren des 16. Jahrhunderts einsetzende Konfessionalisierung wissen wir bisher kaum Genaueres. Der Grund für diese Forschungslücke liegt z. T. im weitgehenden Fehlen städtischer Visitationsakten. Die Aussage dieser Quellen hat Gerald Strauss zum Anlaß genommen, die Tiefenwirkung des Luthertums auf dem Lande in Zweifel zu ziehen (Strauss 1975 und 1978; dazu differenzierend: Davis 1982,

22. Dazu ergänzend demnächst auch Thomas $A$. Brady, Jr.; Between Commune and Caesar. Cities, Crown and Reformation, 1450-1550, Kap. 6.

23. Auf die Spitze getrieben wird diese Hervorhebung in Moeller 1979 b, z. B. ebda., 266: "To be sure ... there were certain distortions and misunderstandings of Luther's original intentions. But compared with the deformations and misunderstandings by men such as Franz von Sickingen, or Thomas Munzer, and in the peasants' twelve articles, or in the ecclesiastical regime of the principalities, the urban movement presents a relatively unified picture. In such a comparison Zwingli and Bucer, Lazarus Spengler and Jacob Sturm, Jurgen Wullenwever and John Calvin must be reckoned genuine Lutherans." 
$330)^{24}$. Kritisch hat sich jüngst zu dieser Interpretation James Kittelson aufgrund einer Untersuchung von Visitationsakten zum Straßburger Territorium geäußert (Kittelson 1982a), während Thomas Robisheaux' Forschungen zu Hohenlohe eher Strauss' Sicht zu bestätigen scheinen (Robisheaux 1981). Es kann hier nicht näher auf diese Arbeiten eingegangen werden; aber die ihnen zugrundeliegende Fragestellung müßte eigentlich auch in die Forschung zur Stadtreformation Eingang finden, denn „das Auseinanderklaffen von Bekenntnis und Bekenntnisverwirklichung ist geradezu zum Signum des konfessionellen Zeitalters geworden (Heckel 1983, 10). Freilich dürfte es, mangels städtischer Visitationsakten, schwierig sein, eine befriedigende Antwort darauf zu finden. Immerhin läßt sich vermuten, daß der Befund für den städtischen Bereich weniger negativ als bei Strauss ausfallen dürfte (vgl. Scribner 1982 b, 4-5) 25 .

5. Durch den soeben angesprochenen Begriff der Zweiten Reformation wird freilich der Vorgang städtischer Reformation nur noch mittelbar tangiert. Wenn wir von den Einzelfällen Bremens und Colmars absehen (s. Moltmann 1958; Greyerz 1980), wo 1581 bzw. um 1589/90 die Zweite Reformation eingeführt wurde, handelte es sich bei diesem Vorgang primär um ein territorialstaatliches Ereignis (dazu Schilling 1981, 387-391; Wohlfeil 1982, 40-41 und 61-62; Vogler B. 1981, 346ff.).

Immerhin wird hier deutlich, daß sich der zeitliche Bezugsrahmen der Forschung in den letzten Jahren stark erweitert hat (vgl. dazu Kittelson 1982 b). Dadurch treten der Calvinismus und - im Falle Bremens und Colmars - die Zweite Reformation neben dem Luthertum als Kräfte hervor, die die Rezeption der reformatorischen Lehren in den Städten in einer Spätphase zu beeinflussen vermochten. Auch ist dadurch deutlich die Tatsache in Erscheinung getreten, $\mathrm{da} ß$ es sich beim Vorgang der Stadtreformation nicht allein um ein Phänomen der ersten Hälfte des 16. Jahrhunderts gehandelt hat, wenngleich die Frage der anfänglichen "Schrittmacherfunktion" (dazu Rublack 1978a) in bezug auf die Spätphase der Stadtreformation kein Thema mehr ist. In dieser Phase hat sich die Reformation nur noch in wenigen Reichsstädten als erfolgreich erwiesen, während sie sich in Territorialstädten nicht mehr durchzusetzen vermochte.

Hans-Christoph Rublack hat in diesem Zusammenhang von ngescheiterten

24. Diese Argumentation weiterfuhrend auch: G. Strauss: Lutheranism and literacy. A reassessment, in: $K$. von Greyer, Hg., Religion (wie Anm. 10).

25. Ansatzweise dazu: $K$. von Greyerz: Religion in the life of German and Swiss autobiographers (16th and early 17th centuries), in: ders., Hg., Religion (wie Anm. 10), wobei sich allerdings der Aussagewert von Autobiographien und Tagebuchern für den angesprochenen Zeitraum auf die städtischen Mittel- und Oberschichten beschränkt. 
Reformationen " gesprochen. Er weist insbesondere in Würzburg und Bamberg, darüber hinaus aber auch in den anderen bischöflichen Residenzstädten Südwestdeutschlands, die Existenz sowohl einer frühreformatorischen Bewegung, wie auch einer protestantischen Bewegung in der zweiten Hälfte des 16. Jahrhunderts nach. Nur in Eichstätt und Freising gab es keine späten Bewegungen. Letztere fielen als Minderheitsbewegungen allesamt gegen Ende des 16. Jahrhunderts dem Ausbau der bischöflichen Landeshoheit, die mit verstärkten tridentinischen Reformmaßnahmen einherging, zum Opfer (Rublack 1978b und 1978 c). Ergänzend wäre darauf hinzuweisen, daß sich dasselbe Phänomen auch in der extremen Südwestecke des Reiches, in der Residenzstadt der Basler Fürstbischöfe, Pruntrut (Porrentruy), nachweisen läßt (zuletzt zusammenfassend Pfister 1974, 244-245 und 292), und wie jüngst gezeigt aurde, auch in Münster im Anschluß an die Niederschlagung des Täuferreichs 1535 (Po-chia Hsia 1983) ${ }^{26}$.

Ich selbst habe, ausgehend von einer Fallstudie zur Einführung der Reformation in Colmar im Jahre 1575, die späten Reformationen in insgesamt sechs Reichsstädten (Colmar, Hagenau, Aalen, Essen, Dortmund und Aachen) näher untersucht (Greyerz 1980; weiterführend zu Aachen jetzt auch: Lepper 1979 und Schmitz 1983; zu Dortmund: Schilling 1982). Dabei zeigte sich, daß der Vorgang der Einführung der Reformation in diesen Städten sich im wesentlichen als Ratsreformation bezeichnen läßt, wobei allein Dortmund eine Ausnahme darstellte. Gegenüber diesem Aspekt würde ich heute wohl noch stärker die Tatsache gewichten wollen, $\mathrm{da} B$ sich in diesen Städten durch den Vollzug der Reformation ein Zustand der Bikonfessionalität ergab, der dem Wesen der frühneuzeitlichen Stadt im Grunde widersprach, weil dadurch die Norm stadtbürgerlicher Einigkeit auf längere Zeit hinaus, wenn nicht sogar auf die Dauer, durchbrochen wurde.

6. Der damit angesprochenen Frage der erst im Westfälischen Frieden in bezug auf die Reichsstädte Augsburg, Biberach, Dinkelsbühl und Ravensburg reichsrechtlich verankerten Parität hat sich die Forschung nach längerer Pause (ältere Arbeiten: etwa Pfeiffer 1955 und 1956) mit neuem Interesse zugewandt. Hat bereits Eberhard Naujoks vor kurzem in einer Studie die "Vorstufen der Parität ${ }^{“}$ in Augsburg in den Jahren 1555-1648 untersucht (Naujoks 1980), wobei die Hintergründe und die Konfliktlösung des Augsburger Kalenderstreits im Zentrum seiner Aufmerksamkeit stehen, so beschäftigt sich Paul Warmbrunn in seiner soeben erschienenen Dissertation mit dem "Zusammenleben

26. Vgl. dazu jetzt auch: Ronnie Po-chia Hsia: Society and Religion in Munster, 1535-1618, ( = Yale Historical Publications, Miscellany 131) New Haven und London 1984. 
von Katholiken und Protestanten " in den erwähnten vier Reichsstädten (Warmbrunn 1983). Er geht dabei auch auf den städtischen Alltag ein, wobei sich im Lichte des täglichen Aufeinander-Angewiesenseins der verschiedenen Konfessionsangehörigen zeigt, daß die auf der höheren Ebene der Ratsherren und Geistlichen ausgetragenen Konflikte das Leben des einzelnen Bürgers weniger tangiert haben, als oft angenommen worden ist ${ }^{27}$. Daneben sind den allerdings relativ kleinen Gruppen der Katholiken bzw. dem Katholizismus des späteren 16. und 17. Jahrhunderts in den protestantischen Reichsstädten Ulm (Lang 1977 und 1980) und Straßburg (Fuchs 1975; Levresse 1977) neuere Untersuchungen gewidmet worden.

7. Bei der Betrachtung der Spätphase städtischer Reformation tritt die Frage des Verhältnisses von Land- bzw. Residenzstädten zum Landesherrn, sowie der Reichsstädte zu benachbarten Fürsten und zu Kaiser und Reich, deutlich in den Vordergrund. Allgemein hat man sich in den letzten Jahren stärker dieser Frage der „Außenbeziehungen“ der Städte und der Rückwirkungen derselben auf den Gang der städtischen Reformation angenommen.

Diese Rückwirkungen trugen Wesentliches zur Radikalisierung der reformatorischen Bewegungen in Mühlhausen in Thüringen und in Münster bei (s. Dülmen 1977). Unverkennbar sind sie aber auch im Lichte der Darstellung, die Sigrid Jahns 1976 zum Thema „Frankfurt, Reformation und Schmalkaldischer Bund" (Jahns 1976) vorgelegt hat. Deutlich wird nicht nur, wie das Verhältnis dieser Reichsstadt zum Kaiser, sondern auch wie ihre nachbarschaftlichen Beziehungen zum Kurfürsten von Mainz (dazu jetzt auch: Decot 1980) und zum hessischen Landgrafen den Rat der Stadt zu einer vorsichtigen Reformationspolitik veranlaßten. Bei der von Martin Brecht (Brecht 1977) dargestellten, vor allem von den Städten Nürnberg, Straßburg und Ulm verfochtenen Strategie einer gemeinsamen und einheitlichen Reformationspolitik der Reichsstädte gegenüber Kaiser und Reich, figurierte Frankfurt daher eher im Hintergrund. Nach Brecht zerbrach diese gemeinsame Politik bereits 1526 an den religiösen Spannungen. Dagegen hat Hans-Christoph Rublack seither auf die von den Reichsstädten am Speyrer Reichstag von 1526 präsentierten Gravamina als "politische Form der Reformation" hingewiesen, die der Reformation Permanenz verliehen habe (Rublack 1980 b), und Georg Schmidt hat kürzlich gezeigt, daß bereits die Verhandlungen des Ulmer Städtetages Ende 1524 zu einem Verzicht auf eine korporativ-städtische Stellungnahme zum Religionskonflikt geführt haben (Schmidt 1983, 66-67).

27. Vgl. dazu jetzt auch: Peter Zschunke: Konfession und Alltag in Oppenheim. Beiträge zur Geschichte von Bevölkerung und Gesellschaft einer gemischtkonfessionellen Kleinstadt in der frühen Neuzeit, VIEG Bd. 115, Wiesbaden 1984. 
Lassen sich bereits die Darstellung Martin Brechts ergänzende Gesichtspunkte aus Erdmann Weyrauchs Studie zu den reformationspolitischen Außenbeziehungen südwestdeutscher Reichsstädte (vor allem Straßburgs und Ulms) gewinnen (Weyrauch 1977), so steht uns demnächst aufgrund soeben abgeschlossener Dissertationen und neuerer Arbeiten, die zum Teil im Erscheinen begriffen sind, eine Differenzierung und - in weiten Teilen - auch eine Revision des von Brecht entworfenen Bildes reichsstädtischer Reformationspolitik der zwanziger Jahre des 16. Jahrhunderts ins Haus. Von Georg Schmidt ist aufgrund seiner Untersuchung der Rolle des Reichsstädtecorpus an Reichstagen der frühen Reformationszeit eine eingehendere Analyse des politischen Moments reichsstädtischer Politik in der Reformationszeit zu erwarten ${ }^{28}$. Heinrich $R$. Schmidt hat neben den Reichstagen auch die Städtetage der 1520er Jahre untersucht und neues Material für die innerstädtische Religionspolitik erforscht. Von Georg Schmidts Beobachtungen abweichend (Schmidt 1983) zeigt er, wie die Stigmatisierung des $\mathrm{Z}$ winglianismus als aufrührerisch die religionspolitische Front der Städte 1525 zerbricht. Er wirft auch neues Licht auf die Reformationen Straßburgs und Nürnbergs und weist, über Vogler 1982 hinausgehend, auf den entscheidenden Einfluß des Gemeinen Mannes bei der Einführung der Reformation in Nürnberg hin ${ }^{29}$. Schließlich wird demnächst eine breit angelegte Studie Thomas A. Bradys die gemeinsame Politik der Städte im südwestdeutschen Raum im Lichte einer Kontinuität erscheinen lassen, die sich über mehr als ein halbes Jahrhundert erstreckt hat, bis sie um die Mitte der zwanziger Jahre des 16. Jahrhunderts unter dem Druck des Gemeinen Mannes in sich zusammenbrach ${ }^{30}$.

Ist durch diese in Aussicht stehenden neuen Arbeiten eine wesentliche Vertiefung unseres Verständnisses der Vorgänge im ersten Jahrzehnt der Reformation zu erwarten, so wissen wir immer noch vergleichsweise wenig über die reformationspolitische Rolle der Städte zwischen 1530/31 und 1545. Ein wichtiges Desideratum wäre in dieser Hinsicht eine entsprechende Untersuchung der Akten des Schmalkaldischen Bundes (vgl. dazu jetzt Brady 1983).

Für die Zeit nach 1530/31 hat Thomas A. Brady durch den Nachweis nicht unerheblicher Straßburger Beteiligung bei der Vorbereitung der württembergi-

28. Vgl. jetzt: Georg Schmidt: Der Städtetag in der Reichsverfassung. Eine Untersuchung zur korporativen Politik der Freien und Reichsstädte in der ersten Hälfte des 16. Jahrhunderts, VIEG Bd.113, Wiesbaden 1984.

29. Heinrich R. Schmidt: Reichsstädte, Reich und Reformation. Korporative Religionspolitik der Städte 1521-1529/30. Noch unveroffentlichte phil.-hist. Diss., Saarbrücken 1983. Erscheint unter obigem Titel 1985 in VIEG.

30. Thomas A. Brady, Jr., Between Commune (wie Anm. 22). 
schen Restitution von 1534 auf eine in dieser Form wohl einmalige Verbindung zwischen Stadt- und Fürstenreformation hingewiesen (Brady 1980). Anton Schindling hat gezeigt, daß die Erfahrungen der evangelischen Reichsstädte in der Regelung der Kirchenguterfrage in der territorialstaatlichen Nutzung von Kirchengütern bei der Errichtung von Landes- und Fürstenschulen Nachahmung fanden (Schindling 1980, 82). In einem wichtigen Aufsatz hat sodann Volker Press die engen personalen Verbindungen zwischen Stadtreformation und territorialer Konfessionalisierung vor allem im süd- und südwestdeutschen Raum untersucht (Press 1980 a). Es wird dabei der dem territorialstaatlichen Beamtentum des späten 16. Jahrhunderts gemeinsame städtische „Background“ deutlich und somit der indirekte Einfluß städtischer Oberschichten, denen diese Beamten entstammten, auf den Vorgang der territorialen Konfessionalisierung. Für den west- und nordwestdeutschen Raum hat Heinz Schilling auf ähnliche Verbindungslinien aufmerksam gemacht (zuletzt: Schilling 1983 a). Einen regional differenzierenden Überblick bietet jetzt Volker Press (Press 1983, $214 \mathrm{ff}$.).

Für den nordwestdeutschen Raum hat Franz Petri die Kontinuität burgundisch-niederländischer Machtpolitik, die erst im niederdeutschen Feldzug Karls V. 1547 ein abruptes Ende nahm, hervortreten lassen (Petri 1978). Dieser Politik eignete zugleich eine anti-reformatorische Stoßrichtung, die - auf dem Weg über den auf die Territorien ausgeübten Druck - auch die nordwestdeutschen Städte zu fühlen bekamen. Zu Recht hebt Petri mit Nachdruck die Bedeutung des Umstandes hervor, daß eine Stadt mit einem derart ausgreifenden wirtschaftlichen und kulturellen Einzugsgebiet wie Köln am alten Glauben festhielt (Petri 1978, 13-14). Wird damit auf die reformationspolitische Rolle von "Zentralorten" innerhalb politischer Landschaften des Reiches hingewiesen, so hat inzwischen Heinz Schilling - im Vergleich zu Petri gewissermaßen mit umgekehrten Vorzeichen - ähnlich argumentiert.

In Heinz Schillings grundlegender, am Beispiel der Grafschaft Lippe entwikkelter Fallstudie zum Thema „Konfessionskonflikt und Staatsbildung “ ist vor allem der Untersuchungsteil zum Verhältnis von landstädtischer Reformation und dem mit dem Vorgang der Konfessionalisierung eng verbundenen Ausbau der lippischen Landeshoheit hier von Belang (Schilling 1981, insbes. 15-150 und 365-391). Im Zentrum dieses Untersuchungsteils steht zunächst die Hansestadt Lemgo, wobei sich, wenn auch unter anderen Vorzeichen, Parallelen zu der von Schilling früher untersuchten Situation in Emden (Schilling 1978; s. dazu auch Schilling 1981, 40-44) ergeben. Wichtig ist nun, daß Schilling seine lokalhistorischen Ergebnisse in enge Beziehung setzt zu den für das ubrige Westfalen und - darüber hinaus - für den gesamten norddeutschen Bereich 
vorliegenden Untersuchungen. Wird zunächst die Schrittmacherfunktion der Reformation in den westfälischen Hansestädten "für die erste und entscheidende Phase der Kirchenerneuerung in Westfalen" betont (Schilling 1981, 73), ergibt sich anschließend ein ähnlicher Befund für die Hansestadtreformation insgesamt. Schilling sieht in diesen Vorgängen eine eigenständige Verlaufsform städtischer Reformation, die er als "Typus der Hansestadtreformation" bezeichnet. Er betont, daß „die Eigenständigkeit dieses Typus ... nicht auf den innerstädtischen Zusammenhängen gründet", sondern darin, daß sich in diesen mittleren und großen Landstädten Norddeutschlands "wichtige Entscheidungsprozesse [vollzogen], die zumeist für das umliegende Landgebiet richtungsweisend wurden" (Schilling 1981, 138). Von der reichsstädtischen Reformation und der Hansestadtreformation sind nach Schilling zu unterscheiden alle jene Fälle, ,in denen die kirchlichen Neuerungen innerhalb der Städte im Rahmen einer territorialfürstlichen Reformation durchgeführt wurden. Das war in einer Vielzahl kleiner und kleinster Städte der Fall“ (Schilling 1981, 139).

Ein solcher Fall ist vor kurzem im Hinblick auf die reformatorischen Vorgänge in der brandenburg-ansbachischen Landstadt Kitzingen von Hans-Christoph Rublack untersucht worden (Rublack 1978 d). Hier ging die zunächst vor allem von den Geistlichen vorangetriebene Reformation nach ihrer Radikalisierung im Jahre 1525 (dazu auch: Bátori 1979) ganz in der Fürstenreformation auf. Deshalb hat Peter Blickle für diesen Fall die Typenbezeichnung nstädtische Fürstenreformation " vorgeschlagen. Zu Recht fügt er freilich einschränkend hinzu: „Inwieweit Kitzingen für die Landstadt Modellcharakter beanspruchen darf, muß mangels detaillierter Monographien zur Reformationsgeschichte der landesherrlichen Städte noch offen bleiben" (Blickle 1982 a, 94-95). Allerdings muß diese Einschränkung nun vor allem auf Oberdeutschland bezogen werden.

7.1. Größere Aufmerksamkeit ist in letzter Zeit auch den Stadt-Land-Beziehungen geschenkt worden, wobei zwischen städtischer Territorialpolitik und städtischen Umlandbeziehungen zu unterscheiden ist. Die Rolle der städtischterritorialen Untertanen im Prozeß der Reformation hat Kurt Maeder am Beispiel Zürichs veranschaulicht, wo die bäuerliche Landschaft in der nach der Schlacht von Kappel 1531 eingetretenen Herrschaftskrise den weiteren Gang der zürcherischen Reformationspolitik in einer wohl entscheidenden Phase in ihrem Sinne zu beeinflussen vermochte (Maeder 1978; vgl. auch Hauswirth 1978). In Bern dagegen, wie Ernst Walder vor kurzem in einer umfangreichen Studie gezeigt hat, verliefen die Dinge in vergleichsweise geordneteren Bahnen. Die Anzeichen der frühen Reformationsjahre, die Reformation selbst könnte eine landständische Verfassungsentwicklung im bernischen Territorium in die Wege leiten, sollten sich nicht bewahrheiten. Durch die 1528 von den Unterta- 
nen vertraglich anerkannte Glaubens- und Kirchenhoheit der städtischen Obrigkeit wurde, nach Walder, "die Voraussetzung für jene vereinheitlichende und integrierende Politik geschaffen, die als ein Kennzeichen der Entwicklung zu ,moderner" Staatlichkeit bezeichnet wurde" (Walder 1980, 530). Damit ist freilich eine weit über den Rahmen des vorliegenden Berichts hinausführende Problematik angesprochen, die einerseits - in bezug auf das noch anzusprechende Verhältnis von Stadt- und Fürstenreformation (s. Teil III) - auf den "Sonderfall Schweiz" hinweist, andererseits die Rolle städtischer Territorien in den reformationspolitischen Entscheidungen der Städte hervorhebt. Ist die Tragweite dieser Erkenntnis für die Betrachtung der Reformation in den eidgenössischen Stadtstaaten von vordringlichem Interesse ${ }^{31}$, so sollte ihre Bedeutung für die nördlicheren deutschen Städtelandschaften im Lichte des starken Süd-Nord-Gefälles der städtisch-territorialen Expansion im Spätmittelalter nicht überschätzt werden (Meuthen 1980, 25 und 131; Leiser 1975, v. a. 968970; zur Territorienbildung der Schweizer Städte vgl. auch Schwarz 1974).

Auf die Bedeutung städtischer Umlandbeziehungen hat Karl Czok verschiedentlich durch seine Studien zur Rolle der Vorstädte in Sachsen und Thüringen hingewiesen (z.B. Czok 1979 und 1980). Auch Rolf Kiessling hat sich dieser Frage angenommen (Kiessling 1977; kritisch dazu: Scott 1979, 958, Anm. 166). Seine kürzlich zu den nicht-institutionellen Memminger Umlandbeziehungen im späten 15. und 16. Jahrhundert vorgelegte Arbeit betont stark den Aspekt der Kontinuität im wirtschaftlichen Bereich und entwirft u. a. das Bild einer expansiven vorreformatorischen Kirchenpolitik Memmingens, die weit über den innerstädtischen Bereich hinausgriff (Kiessling 1980). Thomas A. Brady hat in diesem Zusammenhang die nicht zu unterschätzende Verankerung der städtischen Patriziate und Zunftaristokratien Südwest- und Suddeutschlands, insbesondere Straßburgs und Ulms, im außerstädtischen Lehenswesen hervorgehoben (Brady 1978 a, u. a. 139; Brady 1978 b und Brady 1982, 170). Umlandbeziehungen konnten natürlich auch einen den obrigkeitlichen Handlungsspielraum einengenden Einfluß auf den Gang städtischer Reformationen ausüben, wie dies Hans-Christoph Rublack jüngst erneut am Beispiel des von habsburgischem Gebiet umgebenen EBlingen gezeigt hat (Rublack 1981, 74).

7.2. Im Rahmen der zur Diskussion stehenden städtischen „Außenbeziehun-

31. Differenzierend dazu jetzt die Fallstudie Juliane Kümmells zur Herrschaft Waldenburg auf der Basler Landschaft, wo die Beteiligung an städtisch-politischen Entscheidungsprozessen im Gegensatz zur Zürcher und Berner Lanschaft kaum entwickelt war. Wie Kümmell zeigt, schließt die Reformation in der Waldenburger Herrschaft eine bereits im späteren 15. Jahrhundert einsetzenden und seither kontinuierlichen und gezielten Prozeß des städtischen Herrschaftsausbaus ab (Kümmell 1980/82, $178 \mathrm{ff}$.). 
gen“ muß auch auf das Verhältnis zwischen städtischer Reformation und dem sog. Bauernkrieg hingewiesen werden. Dies kann hier freilich nur in der gebotenen Kürze geschehen (zusammenfassend zur jüngeren Bauernkriegsforschung: u. a. Scott 1979; Hockerts 1979; Scribner 1982 a).

Die seit 1975 intensiv diskutierte These Peter Blickles vom sog. Bauernkrieg als einer "Revolution des Gemeinen Mannes" (Blickle 1975 a und 1981) impliziert, daß die "Revolution von 1525" nicht nur ein Aufstand der Bauern, sondern einer des "Gemeinen Mannes" gewesen sei, d.h. ein Aufstand von Bauern, „Bürger(n) landesherrlicher Städte“, der „nicht ratsfähige(n) Bevölkerung der Reichsstädte" und der "Bergknappen" (Blickle 1975b, 127). Dagegen hat vor allem Heinz Schilling namhaft gemacht:

a) Der den Quellen entnommene und dort vorwiegend propagandistisch verwendete Begriff "Gemeiner Mann" vermöge "realhistorische Abläufe, sowie rechtliche Strukturen nicht adäquat zu erfassen".

b) Die Gleichsetzung von "Gemeinem Mann“ mit nicht-ratsfähigen städtischen Gruppen werde der städtisch-genossenschaftlichen Verfassungsstruktur nicht gerecht, wo „der Bürgerverband ... den Rat noch als sein Organ“ betrachtete.

c) $\mathrm{Daß} 1525$ im städtischen Bereich „seit Jahrhunderten bekannte Konfliktaustragungsmechanismen abliefen", während sich das eigentliche "Neue" vorwiegend auf dem Lande abspielte (Schilling 1975, 237-238; vgl. dazu auch Schulze 1977, 69-70, 74-75, 83-84).

$\mathrm{Zu}$ fragen bleibt hier freilich, wie sich der Bürgerverband in den Augen des Rates, der sich ja auch - wie territoriale Obrigkeiten - des Begriffs nGemeiner Mann" bedient hat, ausgenommen hat, und nochmals, ob sich Schillings Sicht städtischer "Konfliktaustragungsmechanismen" so ohne weiteres auf den südund südwestdeutschen Raum - mithin das Kerngebiet des Aufstands von 1525 - übertragen läßt (s. dazu auch die oben, Teil I, geführte Diskussion). Dieser Einwand zielt allerdings z.T. über Blickles Ansatz hinaus, denn er betont auch in bezug auf die Städte vor allem die politischen und damit auch die verfassungsgeschichtlichen Aspekte der Erhebung von 1525. Dagegen entkräftet Blickle m. E. in der zweiten Auflage seines Buches zur "Revolution von 1525“ den Einwand, der Begriff "Gemeiner Mann" habe in den Quellen einen rein propagandistischen Anstrich (Blickle 1981, 193-195). - Sowohl von Thomas A. Brady wie Heinrich R. Schmidt ist demnächst eine zusätzliche Absicherung der Sicht Blickles zu erwarten ${ }^{32}$.

Auch wenn die Reformation, wie von Bernd Moeller, als ein im Grunde gei-

32. Vgl. Anm. 29 und 30. 
stiger Vorgang begriffen wird, muß sich im Zusammenhang mit der diesem Verständnis entsprechenden Betonung der als grundlegend eingeschätzten Rolle von Buch und Flugschrift bei der Verbreitung reformatorischer Lehren (dazu zuletzt: Moeller 1979 a) implizit eine Trennung zwischen städtischer Reformation und sog. Bauernkrieg ergeben (dazu auch kritisch: Rochler 1981). Hierzu sei schon jetzt auf die Untersuchung Franziska Conrads verwiesen, die nachweisen wird, wie stark die (von den Massen nicht als Theologie der Rechtfertigung verstandene) städtische Reformationstheologie auf die elsässische Landbevölkerung am Vorabend des sog. Bauernkriegs eingewirkt hat. Das wesentliche Verbreitungsmedium war dabei offenbar die Predigt". Damit wird, zumindest aufgrund des regionalen Beispiels, ein offenkundiger Mangel der Interpretation Blickles behoben werden (dazu Scribner 1982 a, 115). Dies darf allerdings nicht darüber hinwegtäuschen, $d a ß$ auch weiterhin kaum irgendwelche präzisere Untersuchungen zur Rezeption reformatorischer Lehren durch einzelne nicht-ratsfähige städtische Bevölkerungsgruppen vorliegen (wie z. B. bei Guggisberg/Füglister 1978; und Mörke 1982). Ein Grundproblem der Sicht Blickles - darauf hat vor allem Tom Scoth, wenn auch vielleicht mit zuviel Nachdruck, hingewiesen (Scott 1979, 957-961; dazu auch - modifizierend: Scribner 1982 a, 115) - resultiert aus seiner Festschreibung der politisch-ideologischen Grundlagen des Zusammengehens von städtischen Bevölkerungsgruppen und Bauern, weil sich damit die Neigung verbindet, die soziale und wirtschaftliche Komplexität des Stadt-Land-Verhältnisses zu unterschätzen (vgl. dazu auch Scott 1978/79).

Die künftige Forschung sieht sich damit mit verschiedenen Problembereichen konfrontiert, im Rahmen derer Blickles Interpretation des sog. Bauernkriegs als „Revolution des Gemeinen Mannes" stärkerer empirischer Absicherung bedarf. Dazu gehören die Rezeption reformatorischer Lehren durch einzelne Gruppen städtischer Bevölkerung und die Frage, wie und inwiefern diese die Aufstandsbereitschaft dieser Gruppen erhöht hat; dazu gehören auch die sozialen und wirtschaftlichen Aspekte des Stadt-Land-Verhältnisses und die Frage, welche städtischen Gruppen ein Zusammengehen mit der aufständischen Landbevölkerung befürworteten. Ganz allgemein geht es dabei auch um eine neue umfassende Untersuchung der städtischen Unruhen der Jahre 1524-26 als einer relativ dringlichen Aufgabe künftiger Forschung (zu den gen. Desiderata: Hockerts 1979, 13; Scott 1979, 963; Sea 1979, 5; Scribner 1982 a, 118).

Damit sind weitgehend Aufgaben genannt worden, die sich auch der künftigen marxistisch-leninistischen Interpretation der deutschen Geschichte der

33. Wie Anm. 14. 
Jahre 1517 bis 1526 als „frühbürgerlicher Revolution“ stellen (zur älteren Diskussion dieser Interpretation s. die Beiträge in Wohlfeil 1975; und Foschepoth 1976). Einen guten Überblick über diese Forschung im letzten Jahrzehnt, wenn auch keine inhaltliche Analyse, bietet Max Steinmetz (Steinmetz 1980). Wird im Rahmen dieses Verständnisses weiterhin davon ausgegangen, daß die frühbürgerliche Revolution ,im Zeichen der städtisch-bürgerlich geprägten Reformationsbewegung begann und die agrarisch-bäuerliche Komponente erst auf deren Höhepunkt - im Bauernkrieg der Jahre 1524/25 - ins Zentrum rückte" (Heitz/Vogler 1980, 1066), so wird nunmehr angesichts der „starken Gegensätze zwischen Stadt und Land“ und der zu schwachen „antifeudalen Ressentiments des Stadtbürgertums“ (Heitz/Vogler 1980, 1066) nur der revolutionäre ideologische Charakter der als bürgerlich verstandenen Reformation betont, und zwar nur insofern, als "die Reformation eine Massenbasis in den mittleren und unteren Schichten der Gesellschaft besaß, so daß sie von der Masse der Gläubigen oder von der Obrigkeit auf ein entsprechendes Drängen „von untẹn " durchgesetzt wurde (Hoyer 1980, 15). Der "Klasseninhalt" der deutschen frühbürgerlichen Revolution wird jetzt dagegen vor allem darin gesehen, „daß der revolutionäre Kulminationspunkt weithin von bäuerlichen Interessen bestimmt wurde" (Heitz/Vogler 1980, 1071). Deshalb wird von Adolf Laube gegenüber Blickles These von der "Revolution des Gemeinen Mannes“ namhaft gemacht, „daß sich die Einheit von Reformation und Bauernkrieg auf den ,inneren Zusammenhang' beziehe, nicht aber auf die , sie tragenden Klassenkräfte" (Zitat nach Rochler 1981, 20; s. auch Laube 1978, 612 und Vogler, G. 1982, 323). Dazu Laube weiter: „Die Volksmasse - der ,gemeine Mann` - spielten die entscheidende Rolle als Triebkraft der Revolution des frühen 16. Jahrhunderts; der Charakter der Revolution war aber nicht der einer ,Revolution des gemeinen Mannes', sondern der einer frühen noch unausgereiften Form der bürgerlichen Revolution" (Laube 1978, 614; Hervorhebung: K.v.G.). Nicht unberechtigt ist daher der Einwand Peter Blickles, daß unter diesen Umständen eher von einer "vorbürgerlichen" Revolution gesprochen werden sollte (Blickle 1982 a, 125). Zurecht weist Wolfgang Rochler auf die hier zutage tretende „deutliche Verlagerung der Problematik der Volksreformation in den Bereich methodologischer Abstraktion" hin (Rochler 1981, 20). Dadurch erschwert sich freilich die marxistisch-leninistische Forschung den noch fälligen empirischen Nachweis der subjektiv revolutionären Rolle des städtischen Bürgertums außerordentlich (kritisch dazu: Hockerts 1979, 1-4; Wohlfeil 1982, 197). Gegen die Annahme objektiv revolutionärer Bedingungen, d.h. einer ngesamtgesellschaftlich wirksamen Krise ..., die in eine frühbürgerliche Revolution als gesetzmäBige Folge einmünden konnte“, hat vor kurzem Rainer Wohlfeil aufgrund sei- 
nes a.a.O. breiter entwickelten (Wohlfeil 1982, 123-133) Begriffs der ${ }_{n}$ reformatorischen Öffentlichkeit" argumentiert (Wohlfeil 1980). Auf die zu erwartende Reaktion auf Wohlfeils Kritik in den noch ausstehenden Publikationen zu den Veranstaltungen des Lutherjahres 1983 darf man gespannt sein.

7.3. Im Zeichen der Frage städtischer „Außenbeziehungen“ haben auch das von Karl V. oktroyierte Augsburger Interim und dessen Auswirkungen in evangelischen Städten in den letzten Jahren, nicht zuletzt auch in den oben (6.) bereits erwähnten neueren Untersuchungen zur Paritätsfrage in bikonfessionellen oberdeutschen Reichsstädten, vermehrte Aufmerksamkeit gefunden. Bisher liegt allerdings erst eine einzige, neuere monographische Studie zu diesem Thema vor. Es handelt sich um Erdmann Weyrauchs interessante, sozialgeschichtlich-systemtheoretische Arbeit zum Interim in Straßburg, die die Vorgänge in der oberrheinischen Reichsstadt bis 1561 verfolgt, als die vorubergehend dem katholischen Kultus geöffneten beiden Stiftskirchen und das Münster wieder ausschließlich für den protestantischen Gottesdienst benützt wurden (Weyrauch 1978). Das Interim wird als konfessionelle und „bestandsgefährdende Systemkrise" Straßburgs bezeichnet. Wie die oben diskutierte Darstellung Bradys (Brady 1978 a) zeigt, trifft dies für die Jahre 1547/48 bestimmt zu. Ob Weyrauch für die Zeit danach, wie Anton Schindling vermutet (Schindling 1981, 181-182), den gewissermaßen systemimmanenten Zwang zur Abschaffung des Interims nicht vielleicht zu stark von funktionalen Gesichtspunkten her beurteilt, müßte vor allem auch auf vergleichender Grundlage weiter diskutiert werden. Dazu fehlen aber $\mathrm{z}$. $\mathrm{Zt}$. noch ähnliche monographische $\mathrm{Ab}$ handlungen zu weiteren oberdeutschen Reichsstädten.

Allerdings zeigt die neulich von Hans-Christoph Rublack untersuchte Situation in Eßlingen und Nördlingen, daß sich andernorts die Laien kaum aktiv dem Interim widersetzten. In Nördlingen - freilich ein „Extremfall“ - stieß der Widerstand der evangelischen Geistlichen gegen die kaiserliche Maßnahme bei der Gemeinde sogar auf verbreitetes Unverständnis, und in Eßlingen konnte sich der Rat sehr viel Zeit lassen, bis er im Jahre 1567 zur endgüligen Abschaffung des Interims schritt (Rublack 1981, 73 und 87-89; Rublack 1982, 250251). Andererseits betont Franz Petri in bezug auf die im Zuge der kaiserlichen Interimspolitik von Brussel aus unterstützten, letztlich erfolglosen Rekatholisierungsbestrebungen in nordwestdeutschen Städten, wie in Osnabrück, Minden und Soest, daß in diesen Städten "wie in der Fruhzeit der reformatorischen Bewegung in den zwanziger Jahren ... der Wille zur Selbstbehauptung in den breiten Schichten der städtischen Bevölkerung, beim gemeinen Mann, ganz besonders ausgeprägt " gewesen sei (Petri 1978, 31).

Trotz dieses konfessionspolitischen Vorstoßes Karls V. in Nordwestdeutsch- 
land ist zu bedenken, daß sich das Interim überhaupt nur dort durchsetzen ließ, wo kaiserliche Macht real präsent war", d.h. hauptsächlich in den oberdeutschen Reichsstädten (s. Wohlfeil 1982, 36). Unter den nord- und mitteldeutschen Städten hat nur die bis 1547/48 von Hessen und Sachsen besetzte Reichsstadt Mühlhausen das Interim mehr als formal angenommen, worin sich - wie Rolf Decot vermutet (Decot 1980, 103-104) - „ein Stück Selbstbehauptung gegenüber den protestantischen Nachbarn erblicken " läßt.

Reichspolitisch gesehen wurde die Position der Städte durch die Ereignisse der Jahre 1547-1555 dauerhaft geschwächt. Die Kirchengüterfrage wurde aufgrund dieser Vorgänge für die Zukunft zur "Achillesferse der evangelischen Reichsstädte" (Schindling 1980, 83).

8. Mit der Kirchengüterfrage rückt als hier abschließend zu behandelnder Aspekt des Themas "Stadt und Reformation" das städtisch-reformatorische Kirchenregiment in unser Blickfeld. In diesem Bereich konnte der Rat der evangelischen Stadt auf einer Tradition aufbauen, die - bei allen lokalen Unterschieden - weit ins Spätmittelalter zurückreichte, insbesondere in der Verwaltung von Kirchengütern durch städtische Kirchenpfleger, in der städtischen Verwaltung der früher rein kirchlichen Spital- und Armenfürsorge und zum Teil auch in der städtischen Kontrolle über das ehemals kirchliche Schulwesen. Nicht nur im Zusammenhang mit den oben (7.) erwähnten Verbindungen $z w i$. schen städtischer und territorialer Reformation, sondern auch im hier diskutierten Fragenbereich wird freilich die Forschung erst noch auf breiterer Basis, wie dies Heinz Schilling gefordert hat, "das reformatorische Geschehen in den Städten als Teil eines übergreifenden Entwicklungsprozesses" zu erfassen haben, der zeitlich und zum Teil in der Sache weit über die Kontinuität mittelalterlicher Elemente hinausführt (s. Schilling 1979, 237). Im Lichte dieser zutreffenden Bemerkungen muß auch deutlich werden, daß der Begriff der „Einführung " in der Tat "wenig zur Erhellung des Tatbestandes der Reformation in den Städten" beiträgt (so Wettges 1978, 7), und daß dadurch die Vorstellung von der Reformation als einer "Revolution gegen die alte Kirche“ (Becker 1983, 108 et passim) relativiert wird.

Beim Ausbau des reformatorischen Schulwesens spielte die Kirchengüterfrage in den Städten eine wichtige Rolle (Schindling 1980). Anton Schindling hat uns auch darauf aufmerksam gemacht, daß die Reformation als eine schulund universitätsgeschichtliche Epoche zu betrachten ist ${ }^{34}$. Dieser Epochencharakter wurde in seinen Anfängen gerade von den Städten in entscheidender Weise mitgestaltet. Entsprechend lassen sich die sich aus diesen Anfängen in

34. Schindling 1982; dort Anm. 5 die neuere, weiterführende Literatur. 
späteren Jahrzehnten des 16. Jahrhunderts entwickelnden Hochschulen Straßburgs und Nürnbergs (Altdorf) als eigenständiger Typus der reichsstädtischen Hochschule bezeichnen (Schindling 1977, 390). In besonderem Maße gilt dies auch für die Schweiz, wo sich in Zürich, Bern, Lausanne und Genf nein einheitlicher Schultypus entwickelt(e), der eine selbständige eidgenössisch-reformierte Lösung des Schul- und Hochschulproblems des Späthumanismus darstellt (e) ${ }^{\mu}$ und in den reformierten Hohen Schulen Deutschlands Nachahmung finden sollte (Im Hof 1977, 57-58). Auf der Ebene der Bildungsinhalte sollte allerdings die wesentliche Kontinuität humanistischer Bildung nicht verkannt werden. Sie war aufgrund der lokalen konfessionspolitischen Situation im Basel des späteren 16. Jahrhunderts besonders ausgeprägt (dazu zuletzt: Guggisberg 1982, 37 ff.), während sie anderswo nals Schulhumanismus vulgarisiert" im konfessionell geprägten Erziehungswesen weiterlebte (zusammenfassend: Meuthen 1983, 226-28; Spitz 1975, 434-36) "s.

Stärker als beim Schulwesen ist bei der Betrachtung des städtischen Armenwesens der Reformationszeit an der grundsätzlichen Kontinuität $z$ wischen der Fürsorgepolitik des 15. und 16. Jahrhunderts festzuhalten (s. z. B. Maschke 1967, 73; Stupperich 1979; Fischer 1979, 155 ff.; Reinhard 1981, 275). Erweist sich zum Beispiel die dem Nürnberger Modell nachgebildete Kitzinger Kastenordnung von 1523 nals Element der reformatorischen Umgestaltung der Stadt aus" (Rublack 1978 d, 55), so ist es nach Hans-Christoph Rublack "nicht ohne weiteres möglich, die Tatsache der Übernahme der Kitzinger Ordnung [in einem Entwurf einer Würzburger Kastenordnung von 1524, K.v. G.] allein schon als Indiz für reformatorische Neigungen des Würzburger Rates oder eines Teiles der Bürgerschaft zu werten" (Rublack 1978 c, 45 und auch 128-143). „Die Bedeutung der Reformation lag dagegen darin, daß durch sie die Almosenvergabe den alten kirchlichen Institutionen entzogen wurde und daß man neue Unterstützungsformen ... nicht nur propagierte - dies gab es auch im katholischen Bereich - sondern vielfach auch praktizierte. Damit setzte sich in den reformierten Städten ein allgemeines Bettelverbot durch, welches in den katholischen Städten in dieser umfassenden Form nicht existierte " (Fischer 1979, 181). In Hamburg ergab sich in diesem Zusammenhang eine besonders enge Verbindung der Reformation des Kirchen- und Armenwesens (vgl. Postel 1980a). Wie in Hamburg, so wurden auch in Lüneburg und Braunschweig außergewöhnlich viele Mitglieder des Bürgerausschusses der Reformationsjahre in der Folge zu Armenkastenherren (s. Mörke 1983, 201 und 216). Die Besonderheit der (ober-

35. Der thematische Schwerpunkt von Moeller/Patzke/Stackmann 1983 liegt dagegen, trotz des Titels, weitgehend im Spätmittelalter. 
deutsch-)schweizerischen Reformation lag darin, daß die in Schaffhausen, $Z \ddot{u}$ rich, Basel und Bern zwischen 1524 und 1528 entstehenden Armenordnungen eng mit der Frage der Kirchen- und Sittenzucht verbunden wurden (Stupperich 1979, 33; auch Moeller 1964, 156-157). Wie sehr dieses Junctim die Zürcher Armenpolitik zur Zeit Heinrich Bullingers (1575) auch noch unter völlig veränderten konjunkturellen Bedingungen prägte, hat Hans Ulrich Bächtold anschaulich gezeigt (Bächtold 1982, $233 \mathrm{ff}$.).

Damit ist ein dritter Aspekt städtisch-reformatorischen Kirchenregiments angesprochen, der hier mangels neuerer, über den lokalen Rahmen hinausgreifender Untersuchungen nur gestreift werden kann. Noch immer muß hier auf die ältere zweibändige Darstellung Walter Köhlers mit dem Titel „Zürcher Ehegericht und Genfer Konsistorium“, die auch den süddeutschen Bereich miteinbezieht, hingewiesen werden (W.Köhler 1932/42). Eine Aufarbeitung des von Köhler vor allem aus kirchen- und institutionengeschichtlicher Perspektive bearbeiteten Materials unter neueren, insbesondere auch sozialgeschichtlichen Gesichtspunkten, die den Aspekt der Sozialkontrolle mit umfassen würden, stellt ein wichtiges Desiderat dar, zumal Visitationsakten für den städtischen Bereich weitgehend fehlen. Für Emden hat jetzt Heinz Schilling diese Forderungen in einer eingehenden Untersuchung der Tätigkeit des dortigen Presbyteriums in den Jahren 1557 bis 1562 eingelöst (Schilling 1983 b) ${ }^{36}$.

\section{ABSCHLIESSENDE BEMERKUNGEN}

Es muß darauf verzichtet werden, sämtliche bereits erwähnten und diskutierten Probleme, Fragen und Anregungen in die hier anschließenden Schlußbemerkungen einzubringen. Die folgenden kurzen Betrachtungen sind daher eher als Ergänzung denn als Zusammenfassung des Vorangegangenen zu verstehen.

1. Die Untersuchung des Themas "Stadt und Reformation“ braucht sich nicht auf den geographischen Raum des damaligen Reiches und der schweizeri-

36. Für Basel muß jetzt auch auf Safley hingewiesen werden. In dieser sehr kurzen Studie stellt Safley ein rapides Ansteigen der vom Basler Ehegericht verhandelten Fälle ab 1569 fest, welches er im Sinne obrigkeitlicher Sozialkontrolle interpretiert. Allerdings fehlt ein Hinweis auf das Überlappen der Tätigkeit des Stadt- und des Ehegerichts, sowie eine nähere Untersuchung des konjunkturellen Hintergrundes; (auf die sich auf Heiratsalter und vorehelichen Sexualverkehr auswirkende, zunehmende Abschließung der Zünfte weist Lyndal Roper [s. Anm. 16] hin). Vermutlich werden diese Fragen näher behandelt in der angekündigten Monographie von Thomas M. Safley: Let No Man Put Asunder. The control of marriage in the German Southwest, 1550-1600, (= Sixteenth Century Essays and Studies Bd.2), Kirksville, Missouri, 1984. Vgl. dazu auch Safley 1981. 
schen Eidgenossenschaft zu beschränken, wenngleich der städtischen Reformation nur in diesen Bereichen in den frühen Reformationsjahren eine eigentliche Schrittmacherfunktion zukam. Für die Niederlande liegt neuerdings eine knappe zusammenfassende Studie von Jan Juliaan Woltjer (Woltjer 1980) vor, die sich im bezug auf die Phase der Konsolidierung des städtisch-reformatorischen Kirchenregiments durch neuere Untersuchungen Heinz Schillings ergänzen läßt (Schilling 1980a und 1980 b).

Für die calvinistischen Bewegungen in französischen Städten liegt weiterhin noch keine zusammenfassende Darstellung vor. Hinzuweisen ist hier in erster Linie auf die 1980 erschienene Arbeit von Jeanine Garrison-Estèbe über die Protestanten Südfrankreichs der zweiten Hälfte des 16. Jahrhundert, die enge Verbindungen zwischen den Reformierten in den Städten und unter dem Adel nachweist, und sich dadurch für den Vergleich mit der niederländischen Situation empfiehlt (Garrison-Estèbe 1980). Dagegen ist Philip Benedicts neue Studie über Rouen ganz auf den lokalen Rahmen zugeschnitten, empfiehlt sich aber vor allem aufgrund der in ihr erfolgreich angewendeten, neuartigen sozialgeschichtlichen und auch historisch-anthropologischen Ansätze (Benedict 1981).

2. Neu überdacht werden sollte im Rahmen der angesprochenen Themen die Rolle des Humanismus im städtisch-lokalen Bereich, nicht allein in seiner bildungspolitischen (dazu: Schindling 1981, 188), sondern auch in seiner reformations-politischen Haltung und Rolle schlechthin ${ }^{37}$. Bei einer umfassenderen Untersuchung dieser Frage, insbesondere auch des Einflusses von Humanisten auf die jeweilige städtische Reformationspolitik gegenüber Kaiser und Reich, müßten freilich auch geistesgeschichtlich weniger nergiebige ${ }^{a}$ Humanisten lokalen Zuschnitts berücksichtigt werden (Maeder 1970,41-42). Wie das Beispiel Colmars zeigt, konnten solche Humanisten eine nicht unwesentliche Rolle spielen (s. Greyerz 1980, 84-90). Hier ist auch an die jüngst von Heinrich Lutz geäußerten Gedanken über die Bedeutung der humanistischen "via media“ zu erinnern (Lutz 1979, 126 und 139; s. auch Wohlfeil 1982, 112-117, und Maeder 1970).

3. Beim Versuch, den Übergang der von der Forschung weiterhin unumstritten den Städten zugestandenen Schrittmacherfunktion der frühen deutschen Reformationszeit in die sog. Fürstenreformation an einzelnen, reichsgeschichtlich bedeutsamen Ereignissen festzumachen, wie etwa an der württembergischen Restitution von 1534 (s. Oberman 1977, 329 ff.; Oberman 1981), oder an

37. Siehe dazu demnächst auch die Bemerkungen Thomas A.Bradys, Between Commune (wie Anm.22), Kap. 1. 
diesem letzteren Ereignis, sowie an der Niederlage der Münsterer Täufer $1535^{38}$, ist große Vorsicht geboten, denn dieser Übergang ist aufgrund neuerer Forschungen (z. B. Press 1980 a und Schilling 1981) wohl doch insgesamt als fließend anzusehen.

4. Die Frage nach einer generellen Typologie städtischer Reformation muß weiterhin offenbleiben. Sie wird durch neue Einzeluntersuchungen (z.B. Rublack 1982) und durch die neuerdings erfolgte Ausweitung des zeitlichen Bezugsrahmens der Forschung auch auf die zweite Hälfte des 16. Jahrhunderts noch zusätzlich erschwert. Bisher lassen sich drei verschiedene Gruppen von Typologisierungsversuchen unterscheiden.

Zur ersten Gruppe gehören diejenigen Typologisierungsversuche, denen primär die Frage nach dem eigentlichen politischen Movens der städtischen Reformation zugrundeliegt. Es wird dabei von Begriffen wie Volksreformation (a), Ratsreformation (b), städtischer Fürstenreformation (c), und auch von Gemein dereformation (d) (dazu Blickle 1982 a, 95-97) ausgegangen. Im Lichte der neueren Forschung engen $m$. E. die Begriffe $a, b$ und $d$ den Zugriff zu sehr auf innerstädtische Vorgänge ein, und lassen keine hinlänglich deutliche Unterscheidung $z$ wischen verschiedenen Handlungsebenen städtischer Reformation zu. Bei diesen je verschiedenen Handlungsebenen ging es um die Stadt als erste Ebene, und das städtische Umland bzw. Territorium und die Reichspolitik als zweite und dritte Ebenen ". Deutlicher lassen sich die verschiedenen Handlungsebenen allenfalls beim Begriff $c$ unterscheiden. Wenn es auch zutrifft, daß neuerdings "wohl mehrheitlich“ die Auffassung vertreten wird, "die reformatorische Bewegung sei im Reich überwiegend, von unten' nach oben durchgesetzt worden“ (Blickle 1982 a, 96), so kann diese Beobachtung nur für die erste Hälfte des 16. Jahrhunderts, nicht aber für die späten Stadtreformationen Geltung beanspruchen, und der daraus hergeleitete Begriff $d$ verwischt zudem die doch wohl mehr als bloß oberflächlichen Unterschiede zwischen der sog. integrativen Betrachtungsweise und einer stärker sozialgeschichtlich orientierten Sicht städtisch-reformatorischer Vorgänge (s. dazu die Diskussion in Teil I). Die generelle Etikettierung der (Stadt-)Reformation als „konservative Revolution ... von oben“ (Becker 1983, 141) oder als "Ratsreformation“ (Press 1983, 227 ) ist dagegen nur möglich, wenn die Folgen durchwegs vom Verlauf abgeho-

38. Günter Vogler: Die städtische Reformation in Deutschland - ein Modell oder mehrere?, unveroffentlichte Originalfassung eines am 2. April 1981 am King's College, London, in englischer Sprache gehaltenen Tagungsvortrags. Für die freundliche Überlassung des Manuskripts bin ich dem Verfasser sehr zu Dank verpflichtet.

39. Ich stutze mich dabei auf die von G. Vogler (wie Anm. 38) angesteliten Überlegungen zum Verhältnis von Handlungsebenen und Entwicklungsstufen. 
ben werden (vgl. dazu Becker 1983, 128) und der Bewegungscharakter der städtischen Reformation ignoriert aird.

Eine zweite Variante des Typologisierungsversuchs basiert auf der Bestimmung von Verlaufsphasen. So glaubte etwa Steven Ozment das Grundmuster eines Dreischritts feststellen zu können: "Preachers and laymen learned in Scripture provided the initial stimulus; ideologically and socially mobile burghers, primarily from the (larger) lower middle strata, created a driving wedge of popular support; and government consolidated and moderated the new institutional changes" (Ozment 1975, 131). Dagegen hat Hans-Jürgen Goertz namhaft gemacht, daß Phasen 1 und 2 die „interagierende Gruppierung “ von Predigern und Laien, auf die allein der Rat einer Stadt reagiert habe, zu wenig miteinander verbinden würden (Goertz 1982, 184). Hans-Christoph Rublack wiederum hat auf die Zwischenphase hingewiesen, die er "Intervall" nennen möchte, "die nicht mehr unter dem Aspekt des noch nicht Verwirklichten steht, sondern in der sich die Fronten gleichsam die Waage halten, so daß der Konflikt reale Alternativen bietet“ (Rublack 1980a, 195). Ähnlich erblickt in diesem Zusammenhang Günter Vogler hier die Frage nach der zeitlichen Festlegung und Bestimmung des "kritischen Punkts “ in innerstädtischen Konfliktsituationen. Anhand seiner Untersuchung der Reformation in Nümberg unterscheidet er fünf chronologisch gegliederte „Entwicklungsstufen": Vorreformatorische Kirchenpolitik (1), Einleitung des Reformationsprozesses 1517-1521-22 (2), 1521/22-1524/25 (3), Intensivierung „unter dem Druck der revolutionären Bewegung " in Stadt und Land 1524/25 (4) und - ab 1525 - die Übernahme der Führung (in den meisten Fällen) durch die Räte ${ }^{40}$. Das Problematische an einer derartigen zeitlichen Festschreibung von Verlaufsphasen mit mehr als lokalem Gültigkeitsanspruch liegt freilich - wie Vogler selbst hervorhebt - in der von Ort zu Ort verschiedenen zeitlichen Abfolge von "Entwicklungsstufen“ (vgl. dazu auch oben Teil II, 2). So muß wohl auch der Gültigkeitsanspruch des jüngst von Olaf Mörke aufgrund seiner Untersuchung der Reformation in den Hansestädten Lüneburg, Braunschweig und Göttingen vorgeschlagenen Phasenmodells auf die nord- und nordwestdeutsche Stadtreformation beschränkt bleiben, da es dem im süd- und südwestdeutschen Raum zu beobachtenden, entsprechenden Variantenreichtum nicht vollumfänglich gerecht werden kann. Andererseits ließen sich vermutlich die soeben erwähnten Einwände und Vorschläge H. J.Goertz', H.-C. Rublacks und G. Voglers darin unterbringen. Mörkes Überlegungen lassen sich hier nur stark verkürzt wiedergeben (vgl. Mörke 1983, 172-225). Er geht aus von einem Vier-Phasen-Verlaufsmodell und unterscheidet:

40. Ebda.; vgl. dazu jetzt auch Vogler 1982. 
1. Die Phase der nichtöffentlichen Zirkel.

2. Die Phase der beginnenden öffentlichen Reformation.

3. Die Phase des organisierten institutionalisierten Handelns und Verhandelns.

4. Die Phase der reformatorischen Ratspolitik.

Eine dritte Variante des Typologisierungsversuchs ist im Begriff der ${ }_{n}$ Hansestadtreformation“ zu erkennen. Dieser Begriff umschreibt die Ereignisabfolge, die sich im Zusammenhang mit der Reformation in den Hansestädten auf der Handlungsebene "Stadt und Umland “ bzw. ${ }_{n}$ Hansestadt und Territorialstadt" abgespielt hat. Über innerstädtische Phasenabfolgen sagt er nichts aus. Er läßt sich nur höchst unscharf mit dem Begriff der "städtischen Fürstenreformation" vergleichen, weil letzterem Begriff primär die Frage nach dem eigentlichen politischen Movens zugrundeliegt.

Es ist unschwer einzusehen, daß diese begriffliche Vielfalt künftige Typologisierungsversuche erheblich erschweren wird. Ein solcher Versuch wird wohl noch am erfolgversprechendsten sein, wenn er zunächst von der Frage nach Verlaufsphasen ausgeht, und diese anschließend mit den verschiedenen Handlungsebenen zu vermitteln versucht. Ein offensichtliches Grundproblem werden dabei die zum Teil erheblichen lokalen Unterschiede darstellen.

5. Von grundlegender Bedeutung dürfte sich in der künftigen Forschung die stärkere Berücksichtigung mentalitätsgeschichtlicher und vor allem sozialanthropologischer Kriterien erweisen. Dies gilt nicht nur für die Frage der Rezeption der evangelischen Lehre, sondern auch für die vorreformatorische Religiosität des städtischen Bürgertums und auch der unterbürgerlichen Schichten (vgl. dazu die knappe Skizze eines entsprechenden Forschungsprogramms bei Davis 1982, 331-35). Erst auf dieser Basis wird sich zum Beispiel die These Steven Ozments, bei der Reformation habe es sich gerade in den Städten um einen Vorgang der Desakralisierung gehandelt, genauer und auf einer breiteren Basis überprüfen lassen (s. Ozment 1975 und die einschlägige Diskussion bei Rublack 1978 a). Dies setzt m. E. allerdings voraus, daß die religionssoziologischen Grundannahmen der bisherigen Forschung neu überdacht werden.

Dr. Kaspar von Greyen

German Historical Institute London

17 Bloomsbury Square, GB-London WC 1 A $2 L P$ 


\section{ABKÜRZUNGEN}

\begin{tabular}{|c|c|}
\hline AHS & Abhandlungen zur Handels- und Sozialgeschichte \\
\hline ARG & Archiv für Reformationsgeschichte \\
\hline BIHR & Bulletin of the Institute of Historical Research \\
\hline BWKG & Blätter für württembergische Kirchengeschichte \\
\hline $\mathrm{CEH}$ & Central European History \\
\hline GG & Geschichte und Gesellschaft \\
\hline GWU & Geschichte in Wissenschaft und Unterricht \\
\hline $\mathrm{HZ}$ & Historische Zeitschrift \\
\hline QFRG & Quellen und Forschungen zur Reformationsgeschichte \\
\hline RST & Reformationsgeschichtliche Studien und Texte \\
\hline SCJ & Sixteenth Century Journal \\
\hline SFN & $\begin{array}{l}\text { Spätmittelalter und Frühe Neuzeit. Tübinger Beiträge zur Geschichtsfor- } \\
\text { schung }\end{array}$ \\
\hline SG/VAS & $\begin{array}{l}\text { Stadt in der Geschichte. Veröffentlichungen des südwestdeutschen Arbeits- } \\
\text { kreises für Stadtgeschichtsforschung }\end{array}$ \\
\hline SMRT & Studies in Medieval and Reformation Thought \\
\hline SSA/GP & $\begin{array}{l}\text { Société Savante d'Alsace et des Régions de l'Est, Collection „Grandes Publica- } \\
\text { tions" }\end{array}$ \\
\hline SVRG & Schriften des Vereins für Reformationsgeschichte \\
\hline TRE & Theologische Realenzyklopädie \\
\hline VIEG & Veröfentlichungen des Instituts für Europäische Geschichte \\
\hline VKBW & $\begin{array}{l}\text { Veröffentlichungen der Kommission für geschichtliche Landeskunde in Ba- } \\
\text { den-Württemberg }\end{array}$ \\
\hline VSWG & Vierteljahrsschrift für Sozial- und Wirtschaftsgeschichte \\
\hline ZBLG & Zeitschrift für bayerische Landesgeschichte \\
\hline ZG & Zeitschrift fur Geschichtswissenschaft \\
\hline ZGO & Zeitschrift für die Geschichte des Oberrheins \\
\hline $\mathrm{ZHF}$ & Zeitschrift für Historische Forschung \\
\hline ZRG & Zeitschrift der Savigny-Stiftung für Rechtsgesc \\
\hline
\end{tabular}

\section{VERZEICHNIS ZITIERTER PUBLIKATIONEN}

(Vgl. ergänzend die Anmerkungen)

Angermeier 1983 Angermeier, Heinz, Hg.: Säkulare Aspekte der Reformationszeit, Schriften des Historischen Kollegs, Kolloquien Bd.5, München und Wien 1983.

Bächtold 1982 Bächtold, Hans Ulrich: Heinrich Bullinger vor dem Rat. Zur Gestaltung und Verwaltung des Zürcher Staatswesens in den Jahren 1531 bis 1525, Zürcher Beiträge zur Reformationsgeschichte Bd.12, Bern und Frankfurt/M. 1982.

Bainton 1974 Bainton, Roland H.: Women of the Reformation in Germany and Italy, 1. Aufl. 1971, Boston, Mass. 1974. 
Baron 1937 Baron, Hans: Religion and politics in the German imperial cities during the Reformation, in: English Historical Review, 52, 1937, 405-27, 614-33.

Bátori 1975 Bátori, Ingrid: Das Patriziat der deutschen Stadt. Zu den Forschungsergebnissen über das Patriziat besonders der süddeutschen Städte, in: Die Alte Stadt. Zeitschrift $f$. Stadtgeschichte, Stadtsoziologie u. Denkmalpflege, 2, 1975, 1-30.

Bátori 1979 Dieselbe: Ratsherren und Aufrührer. Soziale und okonomische Verhältnisse in der Stadt Kitzingen zur Zeit des Bauernkriegs und der Reformation, in: Mommsen 1979, 149-214.

Bátori 1980 Dieselbe, $\mathrm{Hg}_{\mathrm{g}}$ : Städtische Gesellschaft und Reformation, SFN Bd. 12, Stuttgart 1980.

Bátori/Weyrauch 1982 Dieselbe und Weyrauch, Erdmann: Die bürgerliche Elite in der Stadt Kitzingen. Studien zur Sozial- u. Wirtschaftsgeschichte einer landesherrlichen Stadt im 16. Jahrhundert, SFN Bd.11, Stuttgart 1982.

Becker 1983 Becker, Winfried: Reformation und Revolution. Die Reformation als Paradigma historischer Begriffsbildung, frühneuzeitlicher Staatswerdung und moderner Sozialgeschichte, Katholisches Leben u. Kirchenreform im Zeitalter der Glaubensspaltung Bd.34, 2., erw. Auflage, Münster 1983.

Benedict 1981 Benedict, Philip: Rouen during the Wars of Religion, Cambridge 1981.

Biskup/Zernack 1983 Biskup, Marian u. Zemack, Klaus, Hg.: Schichtung und Entwicklung der Gesellschaft in Polen u. Deutschland im 16. und 17. Jahrhundert, VSWG, Beiheft 74, Wiesbaden 1983.

Blickle 1975 a Blickle, Peter: Die Revolution von 1525, München und Wien 1975.

Blickle 1975b Derselbe: Thesen zum Thema: Der "Bauernkrieg“ als Revolution des "gemeinen Mannes", in: Blickle 1975c, 127-131.

Blickle 1975c Derselbe, Hg.: Revolte und Revolution in Europa. Referate u. Protokolle des Internationalen Symposiums zur Erinnerung an den Bauernkrieg 1525, HZ, Beiheft 4, München 1975.

Blickle 1981 Derselbe: Die Revolution von 1525, 2., neu bearb. u. erw. Aufl., München und Wien 1981 .

Blickle 1982 a Derselbe: Die Reformation im Reich, Uni-Taschenbücher 1181, Stuttgart 1982.

Blickle 1982b Derselbe, Hg.: Bauer, Reich und Reformation. Festschrift f. Günther Franz, Stuttgart 1982.

Boockmann 1975 Boockmann, Hartmut: Zu den geistigen u. religiösen Voraussetzungen des Bauernkrieges, in: Moeller 1975 a, 9-27.

Bornert 1981 Bomert, René: La Réforme Protestante du Culte à Strasbourg au XVIe siècle (1523-1598). Approche sociologique et interprétation théologique, SMRT Bd. 28, Leiden 1981.

Bosse 1970 Bosse, Hans: Marx-Weber-Troeltsch. Religionssoziologie und marxistische Ideologiekritik, Gesellschaft u. Theologie, sozialwissenschaftl. Analysen 2, München und Mainz 1970.

Brady 1978 a Brady, Thomas A., Jr.: Ruling Class, Regime and Reformation in Strasbourg, 1520-1555, SMRT Bd. 22, Leiden 1978.

Brady 1978 b Derselbe: Patricians, Nobles, Merchants. Internal tensions and solidarities in South German urban ruling classes at the close of the Middle Ages, in: Chrisman/Gründler 1978, 38-45, 159-64. 
Brady 1979a Derselbe: "The Social History of the Reformation" between "Romantic Idealism“ and "Sociologism“. A Reply, in: Mommsen 1979, 40-43.

Brady 1979b Derselbe: "Social History of the Reformation" ... A Conference at the Deutsches Historisches Institut London, May 25-27, 1978, in: SCJ 10, 1979, Nr. 1, 89-92.

Brady 1980 Derselbe: Princes' Reformation versus urban liberty. Strasbourg and the restoration in Wurttemberg, 1534, in: Bátori 1980, 265-91.

Brady 1982 Derselbe: Social History, in: Ozment 1982 b, 161-81.

Brady 1983 Derselbe: Phases and Strategies of the Schmalcaldic League. A perspective after 450 years, in: ARG 74, 1983, 162-81.

Brecht 1977 Brecht, Martin: Die gemeinsame Politik der Reichsstädte und die Reformation, in: ZRG, Kan. Abt., 63, 1977, 180-263.

Brecht 1980 Derselbe: Luthertum als politische u. soziale Kraft in den Städten, in: Petrn $1980 \mathrm{~b}, 1-21$.

Broadhead 1980 Broadhead, Philip: Politics and expediency in the Augsburg Reformation, in: Brooks 1980, 53-70.

Brooks 1980 Brooks, Peter Newman, Hg.: Reformation Principle and Practice. Essays in Honour of A. G. Dickens, London 1980.

Burke 1978 Burke, Peter: Popular Culture in Early Modern Europe, New York 1978.

Burke 1981 Derselbe: Helden, Schurken u. Narren. Europäische Volkskultur in der frühen Neuzeit, hg. von R. Schenda, Stuttgart 1981 (= Übersetzung von Burke 1978).

Chrisman 1972 Chrisman, Miriam U.: Women and the Reformation in Strasbourg 1490-1530, in: ARG, 63, 1972, 143-68.

Chrisman 1980 Dieselbe: Lay Response to the Protestant Reformation in Germany, 1520-1528, in: Brooks 1980, 33-52.

Chrisman 1982 Dieselbe: Lay Culture, Learned Culture. Books and social change in Strasbourg, 1480-1599, New Haven und London 1982.

Chrisman/Gründler 1978 Dieselbe und Gründler, Otto, Hg.: Social Groups and Religious Ideas in the Sixteenth Century, Studies in Medieval Culture Bd.13, Kalamazoo, Mich. 1978.

Christensen 1982 Christensen, Carl C.: Reformation and Art, in: Ozment 1982 b, 249_ 70.

Cohn 1979a Cohn, Henry: Reformatorische Bewegung und Antiklerikalismus in Deutschland und England, in: Mommsen 1979, 309-29.

Cohn 1979b Derselbe: Anticlericalism in the German Peasants' War 1525, in: Past and Present, 83, 1979, 3-31.

Czok 1979 Czok, Karl: Die Vorstädte. Ihre Stellung in den Stadt-Land-Beziehungen, in: Konrad Fritze, Eckhard Müller-Mertens u. Johannes Schildhauer, $\mathrm{Hg}$.: Gewerbliche Produktion und Stadt-Land-Beziehungen, AHS Bd. 18, Weimar 1979, 127-35.

Czok 1980 Derselbe: Die Rolle der Vorstädte in Sachsen und Thüringen im Zeitalter der deutschen frühbürgerlichen Revolution, in: Rausch 1980, 227-44, 361-72 (Disk.).

Davis 1974 Davis, Natalie Z.: Some tasks and themes in the study of popular religion, in: Charles Trinkaus und Heiko A. Oberman, $\mathrm{Hg}$.: The Pursuit of Holiness in late medieval and Renaissance Religion, SMRT Bd. 10, Leiden 1974, 307-36. 
Davis 1975 Dieselbe: Society and Culture in early modern France, Stanford 1975.

Davis 1982 Dieselbe: From ${ }_{n}$ Popular Religion“ to Religious Cultures, in: Ozment $1982 \mathrm{~b}, 321-41$.

Decot 1980 Decot, Rolf: Religionsfrieden und Kirchenreform. Der Mainzer Kurfurst und Erzbischof Sebastian von Heusenstamm, 1545-1555, VIEG Bd. 100, Wiesbaden 1980.

Demandt 1978 Demandt, Dieter: Stadtverfassung und Kirchenwesen im spätmittelalterlichen Kitzingen, in: Demandt/Rublack 1978, 9-34.

Demandt 1980 Derselbe: Konflikte um die geistlichen Standesprivilegien im spätmittelalterlichen Colmar, in: Bátori 1980, 136-54.

Demandv/Rublack 1978 Derselbe und Rublack, Hans-Christoph: Stadt und Kirche in Kitzingen. Darstellung und Quellen zu Spätmittelalter u. Reformation, SFN Bd. 10, Stuttgart 1978.

Deppermann 1979 Deppermann, Klaus: Melchior Hoffman. Soziale Unruhen und apokalyptische Visionen im Zeitalter der Reformation, Göttingen 1979.

Dickens 1979 Dickens, Arthur Geoffrey: Intellectual and social forces in the German Reformation, in: Mommsen 1979, 11-24.

Diestelkamp 1982 Diestelkamp, Bernhard, $\mathrm{Hg}_{\mathrm{g}}$ : Beiträge zum spätmittelalterlichen Städtewesen, Städteforschung, Reihe A, Bd. 12, Köln und Wien 1982.

van Dülmen 1977 van Dülmen, Richard: Religionsgeschichte in der Historischen Sozialforschung, in: GG 6, 1980, Heft 1, 36-59.

van Dülmen 1980 Derselbe: Reformation als Revolution. Soziale Bewegung und religiöser Radikalismus in der deutschen Reformation, München 1977.

Ehbrecht 1974 a Ehbrecht, Wilfried: Zu Ordnung und Selbstverständnis städtischer Gesellschaft im späten Mittelalter, in: Blätter für deutsche Landesgeschichte, 110, 1974, 83-103.

Ehbrecht 1974b Derselbe: Bürgertum und Obrigkeit in den hansischen Städten des Spätmittelalters, in: Rausch 1974, 275-94.

Ehbrecht 1978 Derselbe: Verlaufsformen innerstädtischer Konflikte in nord- und westdeutschen Städten im Reformationszeitalter, in: Moeller 1978 b, 27-47.

Ehbrecht 1979 Derselbe, Hg.: Voraussetzungen und Methoden geschichtlicher Städteforschung, Städteforschung, Reihe A, Bd.7, Köln und Wien 1979.

Ehbrecht 1980a Derselbe: Köln-Osnabrück-Stralsund. Rat und Bürgerschaft hansischer Städte zwischen religiöser Erneuerung und Bauernkrieg, in: Petri 1980 b, 23 bis 63 .

Ehbrecht $1980 \mathrm{~b}$ Derselbe, $\mathrm{Hg}$.: Städtische Führungsgruppen und Gemeinde in der werdenden Neuzeit, Städteforschung, Reihe A, Bd. 9, Köln und Wien 1980.

Ehbrecht/Schilling 1983 Derselbe und Schilling, Heinz, Hg.: Niederlande u. Nordwestdeutschland. Studien z. Regional- u. Stadtgeschichte Nordwestkontinentaleuropas im Mittelalter $u$. in der Neuzeit. Franz Petri zum 80. Geburtstag, Städteforschung, Reihe A, Bd. 15, Koln 1983.

Ellermeyer 1980 Ellemeyer, Jürgen: Schichtung u. Sozialstruktur in spätmittelalterlichen Städten. Zur Verwendbarkeit sozialwissenschaftlicher Kategorien in historischer Forschung, in: GG 6, 1980, Heft 1, 125-49.

Endres 1980 Endres, Rudolf: Die deutschen Führungsschichten um 1600, in: Hofmann/ Franz 1980, 79-109. 
Endriss 1967 Endriss, Albrecht: Die religiös-kirchlichen Verhältnisse in der Reichsstadt Wimpfen vor der Reformation, VKBW, Reihe B, Bd. 39, Stuttgart 1967.

Ennen 1980 Ennen, Edith: Die Frau in der mittelalterlichen Stadtgegesellschaft Mitteleuropas, in: Hansische Geschichtsblatter, 98, 1980, 1-22.

Fischer 1979 Fischer, Thomas: Städtische Armut und Armenfürsorge im 15. und 16. Jahrhundert. Sozialgeschichtliche Untersuchungen am Beispiel d. Städte Basel, Freiburg i.Br. und Strassburg, Göttinger Beiträge z. Wirtschafts- u. Sozialgeschichte Bd.4, Göttingen 1979.

Foschepoth 1976 Foschepoth, Joseph: Reformation und Bauernkrieg im Geschichtsbild der DDR. Zur Methodologie eines gewandelten Geschichtsverständnisses, Berlin 1976.

Friedrichs 1975 Friedrichs, Christopher $R$.: Capitalism, mobility and class formation in the early modern German city, in: Past and Present, 69, 1975, 24-49.

Friedrichs 1978 Derselbe: Citizens or subjects? Urban conflict in early modern Germany, in: Chrisman/Gründler 1978, 46-58, 164-69.

Friedrichs 1979 Derselbe: Urban Society in an Age of War. Nördlingen, 1580-1720, Princeton, N.J. 1979.

Fuchs 1975 Fuchs, Franşois-Joseph: Les catholiques strasbourgeois de 1529 à 1681, in: Archives de l'Eglise d'Alsace 38, 1975, 141-70.

Füglister 1981 Füglister, Hans: Handwerksregiment. Untersuchungen und Materialien zur sozialen und politischen Struktur der Stadt Basel in der ersten Hälfte des 16. Jahrhunderts, Basler Beiträge z. Geschichtswissenschaft Bd. 143, Basel 1981.

Garrison-Estèbe 1980 Garrison-Estèbe, Jeannine: Les Protestants du Midi, 1559-1598, Toulouse 1980.

Garside 1966 Garside, Charles, Jr.: Zwingli and the Arts, Yale Historical Publications, Miscellany 83, New Haven und London 1966.

Ginzburg 1976 Ginzburg, Carlo: Il Formaggio e i Vermi. Il cosmo di un mugnaio del cinquecento, Turin 1976.

Ginzburg 1979 Derselbe: Der Käse und die Wurmer. Die Welt eines Mullers um 1600, Frankfurt/M. 1979 (= Übers. v. Ginzburg 1976).

Goertz 1982 Goertz, Hans-Jürgen: Aufstand gegen den Priester. Antiklerikalismus und reformatorische Bewegungen, in: Blickle 1982 b, 182-209.

Greyerz 1980 Greyer, Kaspar von: The Late City Reformation in Germany. The case of Colmar, 1522-1628, VIEG Bd. 98, Wiesbaden 1980.

Grimm 1978 Grimm, Harold J.: Lazarus Spengler. A Lay Leader of the Reformation, Columbus, Ohio 1978.

Guggisberg 1982 Guggisberg, Hans R.: Basel in the Sixteenth Century. Aspects of the City Republic before, during, and after the Reformation, St. Louis, Missouri 1982.

Guggisberg/Füglister 1978 Derselbe und Füglister, Hans: Die Basler Weberzunft als Trägerin reformatorischer Propaganda, in: Moeller 1978 b, 48-56.

Guggisberg/Rotach 1980 Derselbe und Rotach, Peter, Hg.: Ecclesia semper reformanda. Vorträge zum Basler Reformationsjubiläum 1529-1979, Basel 1980.

Händler-Lachmann 1980 Händler-Lachmann, Barbara: Die Berufstätigkeit der Frau in den deutschen Städten des Spätmittelalters und der beginnenden Neuzeit, in: Hessisches Jahrbuch f. Landesgeschichte, 30, 1980, 131-75.

Hamm 1978 Hamm, Berndt: Laientheologie zwischen Luther und Zwingli. Das refor- 
matorische Anliegen des Konstanzer Stadtschreibers Jörg Vögeli aufgrund seiner Schriften von 1523/24, in: Nolte/Tompert/Windhorst 1978, 222-95.

Hauswirth 1978 Hauswirth, René: Stabilisierung als Aufgabe der politischen und kirchlichen Führung in Zürich nach der Katastrophe von Kappel, in: Moeller 1978 b, 99-108.

Heckel 1983 Heckel Martin: Deutschland im konfessionellen Zeitalter, Deutsche Geschichte Bd. 5, Gottingen 1983.

Heitz/Nogler 1980 Heitz, Gerhard und Vogler, Gunter: Agrarfrage, bäuerlicher Klassenkampf und bürgerliche Revolution in der Übergangsepoche vom Feudalismus zum Kapitalismus, in: ZG, 28, 1980, 1060-1078.

Heitzenröder 1982 Heitzenröder, Wolfram: Reichsstädte und Kirche in der Wetterau. Der Einfluß des städtischen Rats auf die geistlichen Institute v. der Reformation, Studien z. Frankfurter Geschichte, Heft 16, Frankfurd/M. 1982.

Historischer Verein 1980 Historischer Verein d. Kantons Bern, $\mathrm{Hg}$ :: 450 Jahre Berner Reformation. Beitrage zur Geschichte der Berner Reformation und zu Niklaus Manuel, Bern 1980.

Hockerts 1979 Hockerts, Hans Günther: Der Bauernkrieg. Frühbürgerliche Revolution, defensive Bauernerhebung oder Revolution des „gemeinen Mannes"?, in: GWU, $30,1979,1-21$.

Hörger 1978 Hörger, Hermann: Kirche, Dorfreligion und bäuerliche Geselischaft. Strukturanalysen zur gesellschaftsgebundenen Religiosität ... aufgezeigt an bayerischen Beispielen, Teil I: Studien zur altbayerischen Kirchengeschichte Bd. 5, München 1978.

Hofmann/Franz 1980 Hofmann, Hans Hubert und Franz, Günther, Hg.: Deutsche Führungsschichten in der Neuzeit. Eine Zwischenbilanz, Deutsche Fuhrungsschichten in der Neuzeit Bd. 12, Boppard am Rhein 1980.

Holborn 1936 Holbom, Hajo: The social basis of the German Reformation, in: Church History, 5, 1936, 330-39.

Hoyer 1980 a Hoyer, Siegfried: Reform-Reformation-Revolution. Versuch einer historischen Standortbestimmung, in: Hoyer 1980 b, 9-18.

Hoyer 1980 b Derselbe, Hg.: Reform-Reformation-Revolution, Leipzig 1980.

Im Hof 1977 Im Hof, Ulrich: Die reformierten Hohen Schulen und ihre schweizerischen Stadtstaaten, in: Maschke/Sydow 1977, 53-70.

Irwin, Joyce Irwin, Joyce: Society and the the sexes, in: Ozment 1982 b, 343-59.

Jahns 1976 Jahns, Sigrid: Frankfurt, Reformation und Schmalkaldischer Bund. Die Reformations-, Reichs- und Bündnispolitik der Reichsstadt Frankfurt am Main 1525-1536, Studien Z. Frankfurter Geschichte, Heft 9, Frankfurt/M. 1976.

Karant-Nunn 1982 Karant-Nunn, Susan C.: Continuity and change. Some effects of the Reformation on the Women of Zwickau, in: SCJ, 12, 1982, Nr. 2, 17-42.

Kiessling 1971 Kiessling, Rolf: Bürgerliche Gesellschaft u. Kirche in Augsburg im Spätmittelalter. Ein Beitrag zur Strukturanalyse der oberdeutschen Reichsstadt, Abhandlungen z. Geschichte d. Stadt Augsburg Bd.19, Augsburg 1971.

Kiessling 1977 Derselbe: Stadt-Land-Beziehungen, in: ZBLG, 40, 1977, 829-67.

Kiessling 1980 Derselbe: Stadt und Kloster. Zum Geflecht herrschaftlicher u. wirtschaftlicher Beziehungen im Raum Mermmingen im 15. und in der ersten Hälfte d. 16. Jahrhunderts, in: Bátori 1980, 155-190. 
Kittelson 1976 Kittelson, James $M$.: Humanism and the Reformation in Germany, in: CEH, 9, 1976, Nr. 4, 303-22.

Kittelson 1982a Derselbe: Successes and failures in the German Reformation. The report from Strasbourg, in: ARG, 73, 1982, 153-75.

Kittelson 1982b Derselbe: The Confessional Age. The Late Reformation in Germany, in: Ozment 1982 b, 361-81

Klingenstein/Lutz 1981 Klingenstein, Grete und Lutz, Heinrich, $\mathrm{Hg}$.: Spezialforschung und "Gesamtgeschichte". Beispiele und Methodenfragen zur Geschichte der frühen Neuzeit, Wiener Beitrage z. Geschichte d. Neuzeit Bd. 8, Wien 1981.

Kocka 1977 Kocka, Jürgen: Sozialgeschichte. Begriff, Entwicklung, Probleme, Göttingen 1977.

Köhler, H.-J. 1981 Köhler, Hans-Joachim, Hg.: Flugschriften als Massenmedium der Reformationszeit, SFN Bd. 13, Stuttgart 1981.

Köhler, W. 1932/42 Köhler, Walter: Zürcher Ehegericht und Genfer Konsistorium, 2 Bde., Quellen u. Abhandlungen z. schweizerischen Reformationsgeschichte Bde. 7 u. 10, Leipzig 1932/1942.

Kohls 1967 Kohls, Emst Wilhelm: Evangelische Bewegung und Kirchenordnung in oberdeutschen Reichsstädten, in: ZRG, Kan.Abt., 53, 1967, 110-34.

Korell 1980 Korell, Günter: Jürgen Wullenwever. Sein sozialpolitisches Wirken in Lübeck und der Kampf mit den erstarkenden Mächten Nordeuropas, AHS Bd.19, Weimar 1980.

de Kroon/Lienhard 1980 de Kroon, Marijn und Lienhard, Marc, Hg.: Horizons européens de la Réforme en Alsace. Mélanges offerts à Jean Rott, SSAGP Bd.17, Strasbourg 1980.

Kümmell 1980/82 Kümmelh Juliane: Bäuerliche Gesellschaft und städtische Herrschaft im Spätmittelalter. Zum Verhältnis von Stadt und Land im Fall Basel/Waldenburg 1300-1535, Konstanzer Dissertationen Bd. 20, Konstanz und Paris 1980/82.

Kurze 1976 Kurze, Dietrich: Der niedere Klerus in der sozialen Welt des späteren Mittelalters, in: Beiträge z. Wirtschafts- u. Sozialgeschichte des Mittelalters. Festschrift für Herbert Helbig, Köln und Wien 1976, 273-305.

Lang 1977 Lang, Peter Thaddäus: Die Ulmer Katholiken im Zeitalter der Glaubenskämpfe. Lebensbedingungen einer konfessionellen Minderheit, Frankfurv/M. und Bern 1977.

Lang 1980 Derselbe: Die katholische Minderheit in der protestantischen Reichsstadt Ulm, in: Sydow 1980 b, 89-96.

Laube 1978 Laube, Adolf: Bemerkungen zur These von der ${ }_{n}$ Revolution des Gemeinen Mannes", in: ZG, 26, 1978, 607-14.

Leiser 1975 Leiser, Wolfgang: Territorien süddeutscher Reichsstädte. Ein Strukturvergleich, in: ZBLG, 38, 1975, 967-81.

Lepper 1979 Lepper, Herbert: Reichsstadt und Kirche im späten Mittelalter u. der friuhen Neuzeit. Aspekte zur Quellenlage und zum Forschungsstand der Geschichte d. Reichsstadt Aachen 1400-1600, in: Ehbrecht 1979, 28-46.

Levresse 1977 Levresse, Pierre: La survie du Catholicisme à Strasbourg au XVle siècle, in: Livet/Rapp 1977, 457-69.

Lienhard 1980 Lienhard, Marc: Mentalité populaire, gens d'église et mouvement evangélique à Strasbourg en 1522-1523. Le pamphlet „Ein brüderlich warnung 
an meister Mathis ...“ de Steffan von Büllheym, in: de Kroon/Lienhard 1980, 37 bis 62.

Livet 1977 Livet, Georges: Jacques Sturm, Stettmeister de Strasbourg. Formation et idées politiques, 1489-1532, in: Livet/Rapp 1977, 207-41.

Livet/Rapp 1977 Livet, Georges und Rapp, Francis, Hg.: Strasbourg au coeur religieux du XVle siècle, SSAVGP Bd. 12, Strasbourg 1977.

Locher 1979 Locher, Gottfried W.: Die Zwinglische Reformation im Rahmen der europäischen Kirchengeschichte, Göttingen 1979.

Lorenzen-Schmidt 1978 Lorenzen-Schmid, Klaus-Joachim: Die Geistlichen der schleswig-holsteinischen Städte vor der Reformation und ihre Stellung in den Stadtgemeinden, in: Moeller 1978 b, 125-27.

Lorenzen-Schmidt 1979 - Derselbe: Zur Stellung der Frau in der fruhneuzeitlichen Städtegesellschaft Schleswigs und Holsteins, in: Archiv f. Kulturgeschichte, 61, 1979, 317-39.

Lorenzen-Schmidt 1980 Derselbe: Die Sozial- und Wirtschaftsstruktur schleswig-holsteinischer Städte zwischen 1500 und 1550, Quellen u. Forschungen z. Geschichte Schleswig-Holsteins Bd.76, Neumünster 1980.

Lutz 1979 Lutz, Heinrich: Reformation und Gegenreformation, Oldenbourg-Grundriß der Geschichte Bd.10, München und Wien 1979.

Mack 1979 Mack, Phyllis: The Wonder-Year, in: James Obelkevich, $\mathrm{Hg}$.: Religion and the People, 800-1700, Chapel Hill, N.C., 1979, 191-220.

Mc Leod 1981 Mc Leod, Hugh: Religion and the People of Western Europe, 1789-1970, Oxford 1981.

Meader 1970 Meader, Kurt: Die Via Media in der Schweizerischen Reformation. Studien zum Problem der Kontinuität im Zeitalter der Glaubenskämpfe, Zürich 1970.

Maeder 1973 Derselbe: Glaubensdiskussion und Meinungsbildung in der Frühzeit der Zürcher Reformation, in: Zürcher Taschenbuch 1973, 12-29.

Maeder 1978 Derselbe: Die Bedeutung der Landschaft fur den Verlauf des reformatorischen Prozesses in Zürich (1522-1532), in: Moeller 1978 b, 91-98.

Maschke 1959 Maschke, Erich: Verfassung und soziale Kräfte in der deutschen Stadt des Spätmittelalters vornehmlich in Oberdeutschland, in: VSWG, 46, 1959, 289-349, 433-476 (jetzt auch in: Maschke 1980, 170-274).

Maschke 1967 Derselbe: Die Unterschichten der mittelalterlichen Städte Deutschlands, in: Maschke/Sydow 1967, 1-74 (jetzt auch in: Maschke 1980, 306-79).

Maschke 1974 Derselbe: Deutsche Städte am Ausgang des Mittelalters, in: Rausch 1974, 1-44 (jetzt auch in: Maschke 1980, 56-99).

Maschke 1980 Derselbe: Städte und Menschen. Beiträge zur Geschichte der Stadt, der Wirtschaft und Gesellschaft 1959-1977, VSWG, Beihefte 68, Wiesbaden 1980.

Maschke/Sydow 1967 Derselbe und Sydow, Jürgen, Hg.: Gesellschaftliche Unterschichten in südwestdeutschen Städten, VKBW Bd. 14, Stuttgart 1967.

Maschke/Sydow 1977 Dieselben, $\mathrm{Hg}$.: Stadt und Universität im Mittelalter und in der früheren Neuzeit, SG/VAS Bd.3, Sigmaringen 1977.

Maurer 1979 Maurer, Justus: Prediger im Bauernkrieg, Calwer theologische Monographien Bd. 5, Stuttgart 1979.

Meuthen 1980 Meuthen, Erich: Das 15. Jahrhundert, Oldenbourg-Grundriß der Geschichte Bd.9, München und Wien 1980. 
Meuthen 1983 Derselbe: Charakter und Tendenzen des deutschen Humanismus, in: $A \boldsymbol{n}$ germeier 1983, 217-66, 266-76 (Disk.).

Moeller 1962 Moeller, Bernd: Reichsstadt und Reformation, SVRG 180, Gütersloh 1962.

Moelier 1964 Derselbe: Die Kirche in den evangelischen freien Städten Oberdeutschlands im Zeitalter der Reformation, in: ZGO, 112, 1964, 147-62.

Moeller 1965 Derselbe: Frommigkeit in Deutschland um 1500, in: ARG, 56, 1965, 5-30.

Moeller 1970/74 Derselbe: Zwinglis Disputationen. Studien zu den Anfängen der Kirchenbildung und des Synodalwesens im Protestantismus, 2 Teile, in: ZRG, Kan. Abt., 56, 1970, 275-324; 60, 1974, 213-364.

Moeller 1975 Derselbe: Hg.: Bauernkriegs-Studien, SVRG 189, Gütersloh 1975.

Moeller 1977 Derselbe: Deutschland im Zeitalter der Reformation, Deutsche Geschichte Bd.4, Göttingen 1977.

Moeller 1978 a Derselbe: Diskussionsbericht, in: Moeller 1978 b, 177-182.

Moeller 1978 b Derselbe, Hg.: Stadt und Kirche im 16. Jahrhundert SVRG 190, Gutersloh 1978.

Moeller 1979 a Derselbe: Stadt und Buch. Bemerkungen zur Struktur der reformatorischen Bewegung in Deutschland, in: Mommsen 1979, 25-39.

Moeller 1979b Derselbe: The town in church history. General presuppositions of the Reformation in Germany, in: Derek Baker, $\mathrm{Hg}$.: The Church in Town and Countryside, Studies in Church History Bd. 16, Oxford 1979, $257-68$.

Moeller 1980 a Derselbe: Stadtreformation und Klassenkampf, in: Gottingische Gelehrte Anzeigen, 232, 1980, 103-112.

Moeller 1980b Derselbe: Die Basler Reformation in ihrem stadtgeschichtlichen Zusammenhang, in: Guggisberg/Rotach 1980, 11-27.

Moeller/Patze/Stackmann 1983 Derselbe; Patze, Hans und Stackmann, Hans, Hg.: Studien zum städtischen Bildungswesen des späten Mittelalters und der fruhen Neuzeit, Abhandlungen d. Akademie d. Wissenschaften in Gottingen, phil.-hist. Klasse IIV/137, Göttingen 1983

Mörke 1982 Mörke, Olaf: Der „Konflikt“ als Kategorie städtischer Sozialgeschichte des 16. Jahrhunderts. Die Reformation in welfischen Hansestädten als Beispiel, in: Diestelkamp 1982, 144-161.

Mörke 1983 Derselbe: Rat und Bürger in der Reformation. Soziale Gruppen und kirchlicher Wandel in den welfischen Hansestädten Luneburg, Braunschweig und Göttingen, Veröffentlichungen d. Instituts f. Historische Landesforschung d. Universität Göttingen Bd. 19, Hildesheim 1983.

Molitor 1976 Molitor, Hansgeorg: Frömmigkeit in Spätmittelalter und fruher Neuzeit als historisch-methodisches Problem, in: Rabe/Molitor/Rublack 1976, 1-20.

Moltmann 1958 Moltmann, Jürgen: Christoph Pezel (1539-1604) und der Calvinismus in Bremen, Hospitium Ecclesiae. Forschungen zur bremischen Kirchengeschichte Bd. 2, Bremen 1958.

Mommsen 1979 Mommsen, Wolfgang, Hg.: Stadtburgertum und Adel in der Reformation. Studien z. Sozialgeschichte der Reformation in England und Deutschland, Veröffentlichungen d. Deutschen Historischen Instituts London Bd. 5, Stuttgart 1979.

Müller 1981 Müller, Gerhard: Reformation und Stadt. Zur Rezeption der evangelischen 
Verkündigung, Akademie d. Wissenschaften u. d. Literatur Mainz, Abhandlungen d. geistes- u. sozialwissenschaftlichen Klasse, Jg. 1981, Nr.11, Mainz 1981.

Muralt 1930 Muralt, Leonhard von: Stadtgemeinde und Reformation in der Schweiz, in: Zeitschrift $f$. Schweizergeschichte, 10, 1930, 349-84.

Naujoks 1980 Naujoks, Eberhard: Vorstufen der Parität in der Verfassungsgeschichte der schwäbischen Reichsstädte (1555-1648). Das Beispiel Augsburgs, in: Sydow 1980 b, 38-66.

Nolte/TompertWindhorst 1978 Nolte, Josef; Tompert, Hella und Windhorst, Christof. Hg.: Kontinuität und Umbruch. Theologie und Frömmigkeit in Flugschriften und Kleinliteratur an der Wende vom 15. zum 16. Jahrhundert, SFN Bd. 2, Stuttgart 1978.

Oberman 1977 Oberman, Heiko A.: Werden und Wertung der Reformation. Vom Wegestreit zum Glaubenskampf, Tübingen 1977.

Oberman 1981 Derselbe: Stadtreformation und Fürstenreformation, in: Spitz 1981, 80-103.

Ozment 1975 Ozment, Steven E. : The Reformation in the Cities. The Appeal of Protestantism to sixteenth-century Germany and Switzerland, New Haven und London 1975.

Ozment 1979 Derselbe: Pamphlets as a source. Comments on Bernd Moeller's "Stadt und Burch", in: Mommsen 1979, 46-48.

Ozment 1982 a Derselbe: Pamphlet literature of the German Reformation, in: Ozment $1982 \mathrm{~b}, 85-105$.

Ozment 1982 b Derselbe, $\mathrm{Hg}$.: Reformation Europe. A Guide to Research, St. Louis, Missouri 1982.

Ozment 1983 Derselbe: When Fathers Ruled. Family Life in Reformation Europe, Cambridge, Mass. und London 1983.

Pariset 1977 Pariset, Jean Daniel: L'activité de Jacques Sturm, Stettmeister de Strasbourg de 1532 à 1553, in: Livet/Rapp 1977, 253-66.

Petri 1978 Petri, Franz: Karl V. und die evangelischen Städte im Nordwestraum während des Ringens um die politisch-kirchliche Ordnung in Deutschland, in: Jahrbuch $\mathrm{f}$. Westfälische Kirchengeschichte, 71, 1978, 7-31.

Petri 1980 a Derselbe: Einführung, in: Petri 1980 b, VII-XIV.

Petri 1980 b Derselbe: $\mathrm{Hg}_{\mathrm{g}}$ : Kirche und gesellschaftlicher $W_{\text {andel }}$ in deutschen und niederländischen Städten der werdenden Neuzeit. Städteforschung, Reihe A, Bd.10, Köln und Wien 1980.

Peyer 1978 Peyer, Hans Conrad: Verfassungsgeschichte der alten Schweiz, Zürich 1978.

Pfeiffer 1955 Pfeiffer, Gerhard: Der Augsburger Religionsfrieden und die Reichsstädte, in: Zeitschrift d. Historischen Vereins für Schwaben, 61, 1955, 213-321.

Pfeiffer 1956 Derselbe: Das Ringen um die Parität in der Reichsstadt Biberach, in: BWKG, N.F. 56, 1956, 3-75.

Pfister 1974 Pfister, Rudolf: Kirchengeschichte der Schweiz, Bd. 2: Von der Reformation zum Zweiten Villmerger Krieg, Zurich 1974.

Po-chia Hsia 1983 Po-chia Hsia, Ronnie: Civic wills as sources for the study of piety in Münster, 1530-1618, in: SCJ, 14, 1983, Nr.3, 321-48.

Postel $1980_{2}$ Posteh Rainer: Horenjegers und Kökschen. Zolibat und Priesterehe in der hamburgischen Reformation, in: Bátori 1980, 221-33. 
Postel 1980 b Derselbe: Bürgerausschüsse und Reformation in Hamburg, in: Ehbrecht 1980 b, 369-83.

Press 1980 a Press, Volker: Stadt und territoriale Konfessionsbildung, in: Petri 1980 b, 251-96.

Press 1980 b Derselbe: Führungsgruppen in der deutschen Gesellschaft im Übergang zur Neuzeit um 1500, in: Hofmann/Franz 1980, 29-77.

Press $198 j$ Derselbe: Die sozialen Folgen der Reformation, in: Biskup/Zemack 1983, 196-243.

Rabe/Molitor/Rublack 1976 Rabe, Horst; Molitor, Hansgeorg und Rublack, Hans-Christoph, Hg.: Festgabe für Ernst Walter Zeeden, RST, Supplement-Bd.2, Münster 1976.

Rapp 1974 Rapp, Francis: Réformes et Réformation à Strasbourg. Eglise et Société dans le diocèse de Strasbourg (1450-1525), Association des Publications près les Universités de Strasbourg - Collection de l'Institut des Hautes Etudes Alsaciennes Bd. 23, Paris 1974.

Rapp 1982 Derselbe: Renzension von Brady 1978 a, in: ARG, 73, 1982, 313-18.

Rausch 1974 Rausch, Wilhelm, Hg.: Die Stadt am Ausgang des Mittelalters, Beiträge z. Geschichte d. Städte Mitteleuropas Bd. 3, Linz 1974.

Rausch 1980 Derselbe, $\mathrm{Hg}$ :: Die Stadt an der Schwelle zur Neuzeit, Beiträge z. Geschichte d. Städte Mitteleuropas Bd.4, Linz 1980.

Reinhard 1981 Reinhard, Wolfgang: Möglichkeiten und Grenzen der Verbindung von Kirchengeschichte mit Sozial- und Wirtschaftsgeschichte, in: Klingenstein/Lutz 1981, 243-78.

Rendtorff 1966 Rendtorff, Trutz: Zur Säkularisierungsproblematik. Über die Weiterentwicklung der Kirchensoziologie zur Religionssoziologie, in: Internationales Jahrbuch f. Religionssoziologie, 2, 1966, 51-72.

Robisheaux 1981 Robisheaux, Thomas: Peasants and pastors. Rural youth control and the Reformation in Hohenlohe, 1540-1648, in Social History, 6, 1981, Nr.3, $281-300$.

Rochler 1981 Rochler, Wolfgang: Martin Luther und die Reformation als Laienbewegung, Institut f. Europäische Geschichte Mainz, Vorträge Nr.75, Wiesbaden 1981.

Rott 1972 Rott, Jean: La Réforme à Nuremberg at à Strasbourg. Contacts et contrastes (avec des correspondances inédites), in: Hommage à Durer. Strasbourg et Nuremberg dans la première moitié du XVle siècle ..., Publications de la Société Savante d'Alsace et des Régions de l'Est, Recherches et Documents Bd.12, Strasbourg 1972, 91-142.

Rott 1977 Derselbe: Jacques Sturm, scolarque de la Haute Ecole (Gymnase) de la Ville de Strasbourg, 1526-1556, in: Livet/Rapp 1977, 243-51.

Rott/Koch 1978 Derselbe und Koch, Gustave: De quelques pamphletaires nobles: I. Hutten, Cronberg et Mathias Wurm de Geudertheim (J. Rott), II. Eckhart zum Drübel (G. Koch), in: Grandes Figures de l'Humanisme Alsacien, Strasbourg 1978, 135-51.

Rublack 1978 a Rublack, Hans-Christoph: Forschungsbericht Stadt und Reformation, in: Moeller 1978 b, 9-26.

Rublack 1978 b Derselbe: Reformatorische Bewegungen in Wurzburg und Bamberg, in: Moeller 1978 b, 109-124. 
Rublack 1978c Derselbe: Gescheiterte Reformation. Frühreformatorische und protestantische Bewegungen in süd- und westdeutschen geistlichen Residenzen, SFN Bd. 4, Stuttgart 1978.

Rublack 1978d Derselbe: Die Reformation in Kitzingen, in: Demandt/Rublack 1978, 34-96.

Rublack 1979 Derselbe: Probleme der Sozialtopographie der Stadt im Mittelalter und in der frühen Neuzeit, in: Ehbrecht 1979, 177-93.

Rublack 1980 a Derselbe: Reformatorische Bewegung und städtische Kirchenpolitik in EBlingen, in: Bátori 1980, 191-200.

Rublack 1980 b Derselbe: Gravamina und Reformation, in: Bátori 1980, 292-313.

Rublack 1981 Derselbe: Eßlingen, die Reformation und das Interim in: EBlinger Studien, 20, 1981, 73-90.

Rublack 1982 Derselbe: Eine bürgerliche Reformation. Nördlingen, QFRG Bd.51, Gutersloh 1982.

Ruthing 1982 Rüthing, Heinrich: Bemerkungen zur Sozialstruktur und Sozialtopographie Höxters am Ausgang des Mittelalters, in: Diestelkamp 1982, 130-43.

Russell 1983 Russell, Paul: ... Common People and the future of the Reformation in the pamphlet literature of Southwestern Germany to 1525, in: ARG, 74, 1983, 122-39.

Safley 1981 Safley, Thomas M.: Marital Litigation in the Diocese of Constance, 1551-1620, in: SCJ, 12,1981, Nr. 2, 61-77.

Safley 1982 Derselbe: To preserve the marital state. The Basler Ehegericht, 1550-1592, in: Journal of Family History, 7, 1982, 162-79.

Schieder 1982 Schieder, Wolfgang: Religion in the social history of the modern world. A new perspective, in: European Studies Review, 12, 1982, 289-99.

Schilling 1975 Schilling, Heinz: Aufstandsbewegungen in der stadtbürgerlichen Gesellschaft des Alten Reichs. Die Vorgeschichte des Münsteraner Täuferreichs, 1525 bis 1534, in: Wehler 1975, 193-238.

- Schilling 1978 Derselbe: Reformation und Bürgerfreiheit. Emdens Weg zur calvinistischen Stadtrepublik, in: Moeller 1978 b, 128-61.

Schilling 1979 Derselbe: Die politische Elite nordwestdeutscher Stadte in den religiosen Auseinandersetzungen des 16. Jahrhunderts, in: Mommsen 1979, 235-308.

Schilling 1980a Derselbe: Calvinistische Presbyterien in Städten der Fruhneuzeit - eine kirchliche Alternativform zur bürgerlichen Repräsentation? (Mit einer quantifizierenden Untersuchung zur holländischen Stadt Leiden), in: Ehbrecht 1980 b, 384-444.

Schilling 1980b Derselbe: Religion und Gesellschaft in der calvinistischen Republik der Vereinigten Niederlande ..., in: Petri 1980 b, 197-250.

Schilling 1981 Derselbe: Konfessionskonflikt und Staatsbildung. Eine Fallstudie uber das Verhältnis von religiösem und sozialem $W$ andel in der Frühneuzeit am Beispiel der Grafschaft Lippe, QFRG Bd.47, Gutersloh 1981.

Schilling 1982 Derselbe: Dortmund im 16. und 17. Jahrhundert. Reichsstadtische Gesellschaft, Reformation und Konfessionalisierung, in: Dortmund - 1100 Jahre Stadtgeschichte, Dortmund 1982, 151-201.

Schilling $1983_{2}$ Derselbe: Wandlungs- und Differenzierungsprozesse innerhalb der burgerlichen Oberschichten West- und Nordwestdeutschlands im 16. und 17.Jahrhundert, in: Biskup/Zemack 1983, 121-73. 
Schilling 1983 b Derselbe: Reformierte Kirchenzucht als Sozialdisziplinierung. Die Tätigkeit des Emder Presbyteriums in den Jahren 1557-1562, in: Ehbrecht/Schilling $1983,261-327$

Schindling 1977 Schindling, Anton: Humanistische Hochschule und Freie Reichsstadt. Gymnasium und Akademie in Straßburg 1538-1621, VIEG Bd.77, Wiesbaden 1977.

Schindling 1980 Derselbe: Die Reformation in den Reichsstädten und die Kirchengüter. Straßburg, Nürnberg und Frankfurt im Vergleich, in: Sydow 1980b, 67-88.

Schindling 1981 Derselbe: Kirche, Gesellschaft, Politik und Bildung in Straßburg, in: Klingenstein/Lutz 1981, 169-88.

Schindling 1982 Derselbe: Die Universität Gießen als Typus einer Hochschulgründung, in: Peter Moraw u. Volker Press, $\mathrm{Hg}$.: Academia Gissensis. Beiträge zur allteren Gießener Universitätsgeschichte, Veröffentlichungen d. Histor. Kommission $f$. Hessen Bd. 45, Marburg 1982, 83-113.

Schlemmer 1975 Schlemmer, Karl: Gottesdienst und Frömmigkeit in Nümberg vor der Reformation, in: Zeitschrift für bayerische Kirchengeschichte, 44, 1975, 1 bis 27.

Schlemmer 1980 Derselbe: Gottesdienst und Frömmigkeit in der Reichsstadt Nümberg am Vorabend der Reformation, Forschungen z. fränkischen Kirchen- und Theologiegeschichte, Würzburg 1980.

Schmidt 1983 Schmidt, Georg: Städtekorpus und Grafenvereine. Möglichkeiten und Grenzen der Zusammenarbeit kleinerer Reichsstädte zwischen dem Wormser und Speyerer Reichstag 1521 bis 1526, in: ZHF, 10, 1983, 41-71.

Schmitz 1983 Schmitz, Walter: Verfassung und Bekenntnis. Die Aachener Wirren im Spiegel der kaiserlichen Politik (1550-1616), Europ. Hochschulschriften, Reihe III, Bd. 202, Frankfurt/M., Bern u. New York 1983.

Schramm 1977 Schramm, Gottfried: Danzig, Elbing und Thorn als Beispiele städtischer Reformation, in: Historia integra. Festschrift für Erich Hassinger, hg. von Helmut Fensle, Wolfgang Reinhard und Emst Schulin, Berlin 1977, 125-154.

Schulze 1977 Schulze, Winfried: Theoretische Probleme bei der Untersuchung vorrevolutionärer Gesellschaften, in: Theorien in der Praxis des Historikers, hg. von Jürgen Kocka, GG, Sonderheft 3, Göttingen 1977, 55-74, 74-85 (Disk.).

Schwarz 1974 Schwarz, Dietrich W. H.: Die Städte der Schweiz im 15.Jahrhundert in: Rausch 1974, 45-59, 60-62 (Disk.).

Scott 1978/79 Scott, Tom: Reformation and Peasants' $W_{2}$ ar in W/aldshut and Environs. A structural analysis, 2 Teile in: ARG, 69, 1978, 82-102; 70, 1979, 140-68.

Scott 1979 Derselbe: The Peasants' W/ar. A Historiographical Review, in: Historical Journal, 22, 1979, 693-720, 953-74.

Scribner 1975 a Scribner, Robert W. (auch: S., Bob): Civic Unity and the Reformation in Erfurt, in: Past and Present, 66, 1975, 29-60.

Scribner 1975 b Derselbe: Memorandum on the appointment of a preacher in Speyer, 1538, in: BIHR, 48, 1975, 248-55.

Scribner 1976 Derselbe: Why was there no Reformation in Cologne? in: BIHR, 49, 1976, 217-41.

Scribner 1977 a Derselbe: Reformation, carnival and the world turned upside-down, in: Social History, 4, 1977, 483-505. 
Scribner 1977b Derselbe: Is there a social history of the Reformation? in: Social History, 4, 1977, 483-505.

Scribner 1978 Derselbe: Sozialkontrolle und die Möglichkeit einer städtischen Reformation, in: Moeller 1978 b, 57-65.

Scribner 1979 a Derselbe: How many could read? - Comments on Bernd Moeller's "Stadt und Buch", in: Mommsen 1979, 44-45.

Scribner 1979b Derselbe: The Reformation as a social movement, in: Mommsen 1979, $49-79$.

Scribner 1980 Derselbe: Practice and principle in the German towns. Preachers and people, in: Brooks 1980, 95-117.

Scribner 1981 Derselbe: For the sake of simple folk. Popular propaganda for the German Reformation, Cambridge 1981

Scribner 1982 a Derselbe: The German Peasants' War, in: Ozment 1982, 107-33.

Scribner 1982 b Derselbe: Religion, society and culture. Reorientating the Reformation, in: History Workshop Journal, 14, Autumn 1982, 2-22.

Sea 1979 Sea, Thomas F.: Imperial Cities and the Peasants' War in Germany, in: CEH, $12,1979,3-37$.

Seebass 1978 a Seebass, Gottfried: Stadt und Kirche in Nürnberg im Zeitalter der Reformation, in: Moeller 1978 b, 66-86.

Seebass 1978 b Derselbe: Zur Beurteilung des Reformatorischen bei Vögeli, in: Nolte/ Tompert/Windhorst 1980, 296-99.

Spitz 1975 Spitz, Lewis W.: The course of German Humanism, in: Itinerarium Italicum. The Profile of the Italian Renaissance in the Mirror of its European Transformations ..., hg. von Heiko A. Oberman u. Thomas A. Brady, Jr., SMRT Bd. 14, Leiden 1975, 371-436.

Spitz 1981 Derselbe, $\mathrm{Hg}$.: Humanismus und Reformation als kulturelle Kräte in der deutschen Geschichte, Veröffentlichungen d. Histor. Kommission zu Berlin Bd. 51, Berlin und New York 1981.

Stafford 1974 Stafford, William S.: Domesticating the clergy. The inception of the Reformation in Strasbourg, 1522-1524, American Academy of Religion, Dissertation Series Nr. 17, Missoula, Montana 1974.

Stafford 1977 Derselbe: Anticléricalisme et mouvement evangélique à Strasbourg, in: $\mathrm{Li}$ vet/Rapp 1977, 63-73.

Steinmetz 1980 Steinmetz, Max: Forschungen zur Geschichte der deutschen frühbürgerlichen Revolution, in: Historische Forschungen in der CDR 1970-1980 ..., ZG, 28, 1980 (Sonderband), 79-98.

Stirn 1977 Stim, Margarete: Die Bilderfrage in der Reformation, QFRG Bd.45, Gütersloh 1977.

Strauss 1975 Strauss, Gerald: Success and failure in the German Reformation, in: Past and Present, 57, May 1975, 30-63.

Strauss 1978 Derselbe: Luther's House of Learning. Indoctrination of the young in the German Reformation, Baltimore und London 1978.

Stupperich 1979 Stupperich, Robert: Art. „Armenfürsorge“, III u. IV, in: TRE Bd.4. 1979.

Sydow 1980 a Sydow, Jürgen: Bürgerschaft und Kirche im Mittelalter. Probleme und Aufgaben der Forschung, in: Sydow 1980 b, 9-25. 
Sydoa 1980b Derselbe, $\mathrm{Hg} .:$ Bürgerschaft und Kirche, SG/VAS Bd.7, Sigmaringen 1980 .

Trüdinger 1978 Trüdinger, Karl: Stadt und Kirche im spätmittelalterlichen Würzburg, SFN Bd.1, Stuttgart 1978.

Vogler, B. 1976 Vogler, Bemard: Le clergé protestant rhénan au siècle de la Réforme (1555-1619), Association des Publications près des Universités de Strasbourg, Paris 1976.

Vogler, B. 1981 Derselbe: Le monde germanique et hélvetique à l'époque des Réformes (1517-1618), 2 Bde., Paris 1981.

Vogler, G. 1982 Vogler, Günter: Nürnberg, 1524/25: Studien zur Geschichte der reformatorischen und sozialen Bewegung in der Reichsstadt, (Ost-)Berlin 1982.

Walder 1980 Walder, Emst: Reformation und moderner Staat, in: Historischer Verein $1980,441-583$.

Warmbrunn 1983 Warmbrunn, Paul: Zwei Konfessionen in einer Stadt. Das Zusammenleben von Katholiken und Protestanten in den paritätischen Reichsstädten Augsburg, Biberach, Ravensburg und Dinkelsbuhl von 1548-1648, VIEG Bd.111, Wiesbaden 1983

Wehler 1975 Wehler, Hans-Ulrich, Hg.: Der deutsche Bauernkrieg, 1524-26, GG, Sonderheft 1, 1975.

Wesoly 1980 Wesoly, Kurt: Der weibliche Bevölkerungsteil in spätmittelalterlichen u. frühneuzeitlichen Städten und die Betätigung von Frauen im zünftigen Handwerk (insbesondere am Mittel- und Oberrhein), in: ZGO, 128, 1980, 69-128.

Wettges 1978 Wettges, Wolfram: Reformation und Propaganda. Studien zur Kommunikation des Aufruhrs in süddeutschen Reichsstädten, Geschichte und Gesellschaft. Bochumer Historische Studien Bd. 17, Stuttgart 1978.

Weyrauch 1976 Weyrauch, Erdmann: Zur Auswertung von Steuerbüchern mit quantifizierenden Methoden, in: Rabe/Molitor/Rublack 1976, 97-127.

Weyrauch 1977 Derselbe: Strasbourg et la Réforme en Allemagne du Sud, in: Livet/ Rapp 1977, 347-68.

Weyrauch 1978 Derselbe: Konfessionelle Krise und soziale Stabilität. Das Interim in Straßburg 1548-1562, SFN Bd.7, Stuttgart 1978.

Weyrauch 1980 Derselbe: Über soziale Schichtung, in: Bátori 1980, 5-57.

Wohlfeil 1975 Wohlfeil, Rainer, Hg.: Der Bauernkrieg 1524-26. Bauernkrieg und Reformation, München 1975.

Wohlfeil 1980 Derselbe: Die Reformation in sozialgeschichtlicher Betrachtungsweise, in: Hoyer 1980, 95-104.

Wohlfeil 1982 Derselbe: Einführung in die Geschichte der deutschen Reformation, Beck'sche Elementarbücher, München 1982.

Woltjer 1980 Woltjer, Jan Juliaan: Stadt und Reformation in den Niederlanden, in: Petri 1980b, 155-67.

Wood 1981 Wood, Merry Wiesner: Paltry peddlers or essential merchants? - Women in the distributive trades in early modern Nuremberg, in: SCJ, 12, 1981, Nr. 2, 3-14.

Zeeden 1964 Zeeden, Emst Walter: Die Entstehung der Konfessionen, München und Wien 1964.

Zmyslony 1977 Zmyslony, Monika: Die Bruderschaften in Lübeck bis zur Reformation, Beiträge z. Sozial- u. Wirtschaftsgeschichte Nr.6, Kiel 1977. 